\title{
A bricolage-style exploratory scenario analysis to manage uncertainty in socio-environmental systems modeling: investigating integrated water management options
}

\author{
Baihua Fu ${ }^{1}$, Joseph H.A. Guillaume ${ }^{2,1}$, Anthony J. Jakeman ${ }^{1}$, Michael J. Asher ${ }^{1}$ \\ ${ }^{1}$ Fenner School of Environment and Society and Institute for Water Futures, Australian National University, \\ Canberra, ACT, Australia \\ ${ }^{2}$ Water \& Development Research Group (WDRG), Aalto University, Finland
}

\begin{abstract}
Exploratory analysis, while useful in assessing the implications of model assumptions under large uncertainty, is considered at best a semi-structured activity. There is no algorithmic way for performing exploratory analysis and the existing canonical techniques have their own limitations. To overcome this, we advocate a bricolage-style exploratory scenario analysis, which can be crafted by pragmatically and strategically combining different methods and practices. Our argument is illustrated using a case study in integrated water management in the Murray-Darling Basin, Australia. Scenario ensembles are generated to investigate potential policy innovations, climate and crop market conditions, as well as the effects of uncertainties in model components and parameters. Visualizations, regression trees and marginal effect analyses are exploited to make sense of the ensemble of scenarios. The analysis includes identifying patterns within a scenario ensemble, by visualizing initial hypotheses that are informed by prior knowledge, as well as by visualizing new hypotheses based on identified influential variables. Context-specific relationships are explored by analyzing which values of drivers and management options influence outcomes. Synthesis is achieved by identifying context-specific solutions to consider as part of policy design. The process of analysis is cast as a process of finding patterns and formulating questions within the ensemble of scenarios that merit further examination, allowing end-users to make the decision as to what underlying assumptions should be accepted, and whether uncertainties have been sufficiently explored. This approach is especially advantageous when the precise intentions of management are still subject to deliberations. By describing the reasoning and steps behind a bricolage-style exploratory analysis, we hope to raise awareness of the value of sharing this kind of (common but not often documented) analysis process, and motivate further work to improve sharing of know-how about bricolage in practice.
\end{abstract}

\section{Keywords}

Exploratory Analysis; Exploratory Modeling; Water Management; Groundwater; Integration

\section{Code availability}

R code and data used to produce results in this paper are available from: http://doi.org/10.5281/zenodo.1465093

Correspondence:

Contact B. Fu at Baihua.fu@anu.edu.au

\section{Cite this article as:}

Fu, B., Guillaume, J.H.A., Jakeman, A.J., \& Asher, M.J.

A bricolage-style exploratory scenario analysis to manage uncertainty in socio-environmental systems modeling: investigating integrated water management options

Socio-Environmental Systems Modelling, vol. 2, 16227, 2020, doi:10.18174/sesmo.2020a16227

This work is licensed under a Creative Commons Attribution-NonCommercial 4.0 International License. 


\section{Introduction}

Modeling is a useful tool for integrated water resource management, especially if the right questions are posited and addressed during the model construction process (Badham et al., 2019). It provides a framework for systematically accounting for physical processes and constraints, such as mass balance, and in the case of integrated modeling, providing explicit representations of socio-environmental relationships between actions and ecological, economic and social impacts. Modeling can promote understanding and help to improve management, but models also act as constraining devices, imposing certain assumptions and perspectives (Landry et al., 1996). Model results are therefore often contested, because one way out of a disagreeable situation is to raise doubts about the model.

To take one high profile example in Australia, questioning the models was one of the responses to the "Guide to the Proposed Murray-Darling Basin Plan" in 2010 (Murray-Darling Basin Authority, 2010). The Guide was intended to seek feedback from stakeholders on a plan to return water to the environment, including through reductions in water allocations to users, and through investment in water efficiency measures (Murray-Darling Basin Authority, 2010). As part of their submission, one irrigation body challenged the approach, questioning the model conceptualizations and the assumptions that went into the models (Murray Irrigation Limited, 2010). They argued that the data "does not match any of the 'famous' numbers that are more commonly used in the irrigation industry." Subsequently, some of these concerns were assessed in an independent review of the science and modeling underpinning the Guide (Pollino et al., 2011). The MDB situation serves to highlight the challenge of dealing with pervasive uncertainty in water management; "deep" uncertainty in particular has been defined as "fundamental disagreement about the driving forces that will shape the future, the probability distributions used to represent uncertainty and key variables, and how to value alternative outcomes" (Lempert, 2002).

On the one hand, a number of well-known strategies do exist to evaluate and/or defend a model. In the field of water resources modeling, strategies and techniques for improving model performance have been studied extensively. Reviews are available on model calibration and validation (Daggupati et al., 2015; Moriasi et al., 2015), evaluation (Bennett et al., 2013; Moriasi et al., 2007), and the analysis of sensitivity (Saltelli, Chan, et al., 2000) and uncertainty (Beck, 1987; Guzman et al., 2015; Refsgaard et al., 2007). Readers are directed to this literature for more detailed discussion. Validation would, for instance, show why the assumptions used are more appropriate than the "famous numbers" in the example situation above, in an endeavour to argue that the model results are sufficiently accurate to lead to action (Refsgaard \& Knudsen, 1996). The validation process could take into account stakeholder information and fitness-for-purpose criteria (Haasnoot et al., 2014). An uncertainty quantification approach would identify the range of outcomes supported by the data (Pappenberger \& Beven, 2006), allowing testing of success. Alternatively, the potential for a successful modeling outcome could be assigned levels of confidence or be accompanied by reporting model performance (Bennett et al., 2013), leaving decision makers to decide what they want to believe. Promises could be made to utilize adaptive management (Williams, 2011) where decisions may be made more favorable in future as knowledge improves. In any particular case, it is possible that a combination of these approaches would be sufficient to alleviate stakeholder objections and allow model results to be more acceptable.

On the other hand, these strategies are unsatisfactory for modeling problems characterized by pervasive uncertainty. Philosophically-speaking, validation of models of natural systems is generally accepted as being impossible because natural systems are never closed, such that results are non-unique (Oreskes et al., 1994). Practically-speaking, there is a lack of suitable observational data, and in many cases unchallenged theory, to test the modeling with sufficient detail. Modelers acknowledge that they make compromises because of limited resources and information constraints. In qualifying the prediction itself, uncertainty quantification and levels of confidence are effectively meta-predictions that may in turn be contested.

All of these approaches treat a model as consolidative (Bankes, 1993), an (uncertain) proxy or surrogate of a system, such that the usefulness of results depends on how well the model is deemed to match the system (which can be assessed through model evaluation). In recognition of this issue, Hodges (1991) introduced a new theory for the use and interpretation of even inadequately validated models. This approach was extended by Hodges and Dewar (1992) and generalized into the alternative paradigm of exploratory modeling by Bankes (1993). The model is viewed simply as a way of assessing implications of assumptions, thereby supporting reasoning and argument more explicitly. The analysis itself may either be adaptive or static (Maier et al., 2016). 
Reasoning within an adaptive approach involves planning for future changes in understanding, whereas the static approach relies on understanding of assumptions at a single snapshot in time. Scenarios are a central concept of many exploratory methods, both adaptive and static. Scenarios can be seen as coherent descriptions of multiple alternative hypothetical futures, arising from different assumptions. It describes how the future will unfold if you take a specific set of assumptions to be true. In their review, Maier et al. (2016) describe this paradigm as exploring multiple plausible futures, in contrast to quantifying future uncertainty or anticipating the future based on best available knowledge. A single model often includes some aspects that are treated as exploratory (e.g. future scenarios) and others as consolidative (e.g. parameterization of the model). However, the two paradigms are distinctly different in their relation to reality.

Bankes (2002) and Lempert (2002) implemented exploratory modeling using large ensembles of computational experiments, agent-based models and visualizations. More recent work includes that of Bankes et al. (2013) and Kwakkel and Pruyt (2013). One option is to look at what assumptions lead to particular outcomes, such as by identifying ranges of variables responsible (Brown et al., 2012; Bryant \& Lempert, 2010) or identifying how far the values of variables would need to change (Ben-Haim, 2006; Guillaume et al., 2016). Another option is to look at what can be said about a problem despite uncertainties, i.e. what holds true in all the scenarios considered plausible (Fu \& Guillaume, 2014; Guillaume et al., 2015), or what is "robust" by some metric (Giuliani \& Castelletti, 2016; Herman et al., 2015; Kwakkel, Eker, et al., 2016; McPhail et al., 2018). An example of these approaches is robust decision making (Hall et al., 2012; Lempert et al., 2003), which iteratively searches for actions with robust outcomes and explores the circumstances leading to failure. Extensions of this basic concept, for example, consider many objectives (Kasprzyk et al., 2013) and allow for adaptation over time (Beh et al., 2015; Hamarat et al., 2013; Maier et al., 2016; Walker et al., 2013). Practical implementations exist for such conceptual advances, for example the Exploratory Modeling Workbench (Kwakkel, 2017) and Project Platypus (Hadka, 2016, 2019) in Python, and several packages in R (Bryant, 2014; Hadka et al., 2015).

Exploratory analysis is, however, considered at best a semi-structured activity. There is no algorithmic way for performing exploratory analysis. The existing canonical techniques such as Info-Gap (Ben-Haim, 2006), Robust Decision Making (Lempert \& Collins, 2007), Scenario Discovery (Bryant \& Lempert, 2010), Multi-Objective Robust Decision Making (MORDM) (Kasprzyk et al., 2013) and Robust Adaptive Design (Hamarat et al., 2013) provide some suggestions on how exploratory analysis can be performed, but they are not the only ways, and have their own limitations. There is a large body of literature comparing these recipes (Buurman \& Babovic, 2016; Gersonius et al., 2015; Hall et al., 2012; Kwakkel, Haasnoot, et al., 2016; Matrosov et al., 2013; Roach et al., 2015; Roach et al., 2016). However each recipe is a list of pre-defined step-wise techniques. It has already been acknowledged that the combination of steps and techniques is unique to the problem (Herman et al., 2015; Kwakkel \& Haasnoot, 2019).

Instead of confining ourselves to existing techniques, we advocate for recognition of bricolage-style exploratory analyses, where instead of following a fixed recipe, the steps and techniques are combined by the analysts so that the processes are adaptive, the methodologies are fit-for-purpose and aligned with the analysts' resources, skill and style. This bricolage-style analysis is consistent with the constructive decision-aiding approach (Tsoukiàs, 2008) where the problem is formulated and evaluated as part of the decision-aiding process, which calls for more flexible and adaptive methods for tool or technique selection. Closely related to multimethodology research and the design sciences (Vaishnavi \& Kuechler, 2007), such a bricolage is gaining recognition as an approach that makes best use of available techniques, recognizing that appropriate existing methods are not always available and that science is not as "clean, simple and procedural" as one might like (Kincheloe, 2001; Yee, 2010).

This article aims to contribute an exemplar of how an exploratory scenario analysis can be crafted by "bricolage", that is, by pragmatically and strategically choosing and applying different methods and practices (Kincheloe, 2005). A hypothetical case study is presented of conjunctive use of surface and groundwater, based on a typical catchment in the Murray-Darling Basin, Australia (Section 2.1), along with an integrated model of the system (Supplementary Material A). Our conceptualization of the exploratory scenario analysis process is then described, highlighting the key practices we selected (Section 2.2). For a selection of scenarios (Section 2.3), the results illustrate the type of reasoning and insights achieved with the process and practices selected (Section 3 ).

Relative to existing literature, our hypothetical case study emphasizes using a range of transferable practices to generate general insights that might be useful for further discussion of the modeling issue at stake. The modeling 
context involves an analyst preparing to give expert advice. Rather than the model results being used directly, the expert is responsible for their interpretation, and communication of any insights to a broader decisionmaking process. This interpretation process then addresses additional issues such as uncertainty in value judgements and contextual framing. To aid transferability, we have tried to explicitly describe each practice in such a way that the reader can evaluate whether they would want to use it in their work. The relation of each practice to existing literature is further discussed in Section 4. Notably, the case study complements another hypothetical example given by Moallemi et al. (2018), which similarly advocates for mixing methods in the context of exploratory modeling, specifically from a multi-method design perspective.

\section{Methods}

\subsection{Hypothetical case study}

We use a hypothetical (but realistic) case study in water resources management to demonstrate the use of exploratory scenario analysis for discovering candidate options and related uncertainties. The case study area is representative of part of the lower Namoi catchment in Australia, which is a semi-arid agricultural catchment. The entire lower Namoi has previously been studied though a more consolidative modeling approach by Letcher et al. (2004), and many lessons especially from the stakeholder engagement aspects of the work are communicated in Croke et al. (2007). Here we describe the system in terms of the XLRM framework of Lempert et al. (2003), which includes exogenous uncertainties (X), policy levers (L), relationships/model (R) and measures or output metrics (M).

This coupled human-natural system has high exogenous uncertainty $(\mathrm{X})$ in terms of both natural variability in the biophysical system as well as gaps in our knowledge about how the biophysical and human system work and interact. Climate and crop market variability, hydrological and hydrogeological behaviors, irrigation efficiency and water requirements of the riparian vegetation all have various levels of uncertainty. The process of defining scenarios for these uncertainties is described in Section 2.3, and summarized in Table 1.

The policy levers (L) of the framework belong to the catchment managers and farmers. The case study here contains one representative farm which grows summer crops such as cotton, maize, sorghum and soybean, and winter crops such as chickpeas, faba bean and wheat. The crops are currently either under flood irrigation or dryland cropping, the latter relying only on rain water. The irrigation water is obtained from the river and groundwater, the amount of which is in part constrained by water allocation rules in the area. Farmers need to make business decisions about crop selection, areas to plant and the means and amount of irrigation in order to make a profit. Policy makers set up water allocation rules that balance water needs, specifically water resources for consumptive users (largely farmers), and protecting the environment, in this case the riparian vegetation along the river. The riparian vegetation (river red gum) relies on regular flooding and suitable groundwater levels to remain healthy.

Water scarcity is one of the major threats to the study area and different adaptation options are being explored at both farm and local water management scale. Adaptation options at farm scale include adopting more efficient and costly systems than flood irrigation, such as drip or spray irrigation. Farmers' attitude towards adopting new technology may also influence its uptake. At a local water management scale, water allocation rules (surface water and/or groundwater) determine how water is shared between irrigators and between irrigators and environment. There are both surface and groundwater allocation rules in place, but their rules are developed and managed separately. All of these adaptation options may change the outcomes in farm profits and environmental health in the area.

The goal of the investigation is to assess the implications of management and policy options in such a representative agricultural and policy landscape given its pervasive uncertainties, including the different value judgements along the anthropocentrism-partnership-ecocentrism spectrum (van Asselt \& Rotmans, 1996). Due to the complexity of the issue, quantitative management objectives are not available. The expectation is that the learning from the analysis can be used to support further system-scale research and deliberation between stakeholder farmers, managers and communities in similarly broad water allocation contexts. To achieve these objectives, computational experiments using an integrated model of the coupled human-natural system are iteratively designed within the context of exploratory scenario analysis (Section 2.2). 
The integrated model $(R)$ was developed to enable the analysis of indicators of the ecological and economic impacts of climate, technology, markets, and policy. A daily hydrological model (including surface and groundwater) (Blakers et al., 2011; Croke \& Jakeman, 2004) interacts with models of annual farmer decisions (Letcher et al., 2004), water policy, and ecology (Fu \& Guillaume, 2014). These component models were evaluated when possible with available observation data. The conceptual diagrams for the integrated model and descriptions of the component models are provided in Supplementary Material A.

Six output metrics (M)/indicators were produced:

- Mean annual farm profit in millions of dollars

- $\quad$ Standard deviation of mean annual farm profit, representing the variation in profit (which may arise from variations in climate, market conditions and farming practices)

- Mean annual suitability index of the flow regime for the maintenance of river red gum

- Mean annual suitability index of the groundwater regime for the maintenance of river red gum

- Mean annual groundwater depth in meters below ground

- Minimum annual groundwater depth in meters below ground

In addition, when evaluating the economic and environmental outcomes, people (e.g. farmers, water managers, communities) have different value judgements in terms of how these outcomes should be balanced when faced with a trade-off. As special cases, some may favour profit over environmental outcome (anthropocentrism), some may favour environmental outcome over profit (ecocentrism), while some may hold a balanced value judgement (partnership) (van Asselt \& Rotmans, 1996). However, most of the time the values lie somewhere along the scale of anthropocentrism and ecocentrism, and the trade-offs are often not "one or the other", but "how much of each".

The results were also aggregated based on assumptions of different value judgements in the community in terms of trade-offs between these outcomes. Because the model outputs are in different units and scales (e.g. profits are in million dollars and groundwater depths range from 7.5-30m), each output type $x$ was firstly rescaled to 01 based on their ranges $\left(x^{\prime}=\left(x-x_{\min }\right) /\left(x_{\max }-x_{\min }\right)\right)$. Then the different indicators were aggregated using weights to reflect a value judgement. Four scenarios were tested as illustration of how values affect results:

- $\quad$ Equal weight: for those valuing farm profit and environment equally, equal weights were given to the profit, groundwater and ecological outcomes.

- $\quad$ Profit-focused: for those valuing profits more than environment, a weight of 0.6 was given to profit, and 0.2 to both ecological and groundwater outcomes.

- $\quad$ Ecology-focused: for those valuing ecological outcomes (river red gum) more than others, a weight of 0.6 was given to ecology, and 0.2 to both profits and groundwater.

- Groundwater-focused: for those valuing sustainability of the groundwater resource, a weight of 0.6 was given to groundwater, 0.2 to both profit and ecology.

Note that this normalization approach may lead to scaled outputs being sensitive to outliers and the range of model outputs. Thus, both pre-aggregated and post-aggregated results were used for exploratory analysis.

\subsection{Exploratory Scenario Analysis}

The integrated model is used in the context of exploratory scenario analysis. The process broadly involves two phases: scenario development (Section 2.2.1) and scenario analysis (Sections 2.2.2-2.2.4) (Figure 1). For the scenario development, we adapted the Exploratory Modeling and Analysis methodology (Bankes et al., 2013; Kwakkel \& Pruyt, 2013) and the Adaptive Robust Design approach (Hamarat et al., 2013), with some modification. The scenario analysis is further separated into identifying patterns (e.g. data distributions, influential variables) (Section 2.2.2), exploring context-specific relationships (Section 2.2.3), and contextual synthesis (Section 2.2.4). 


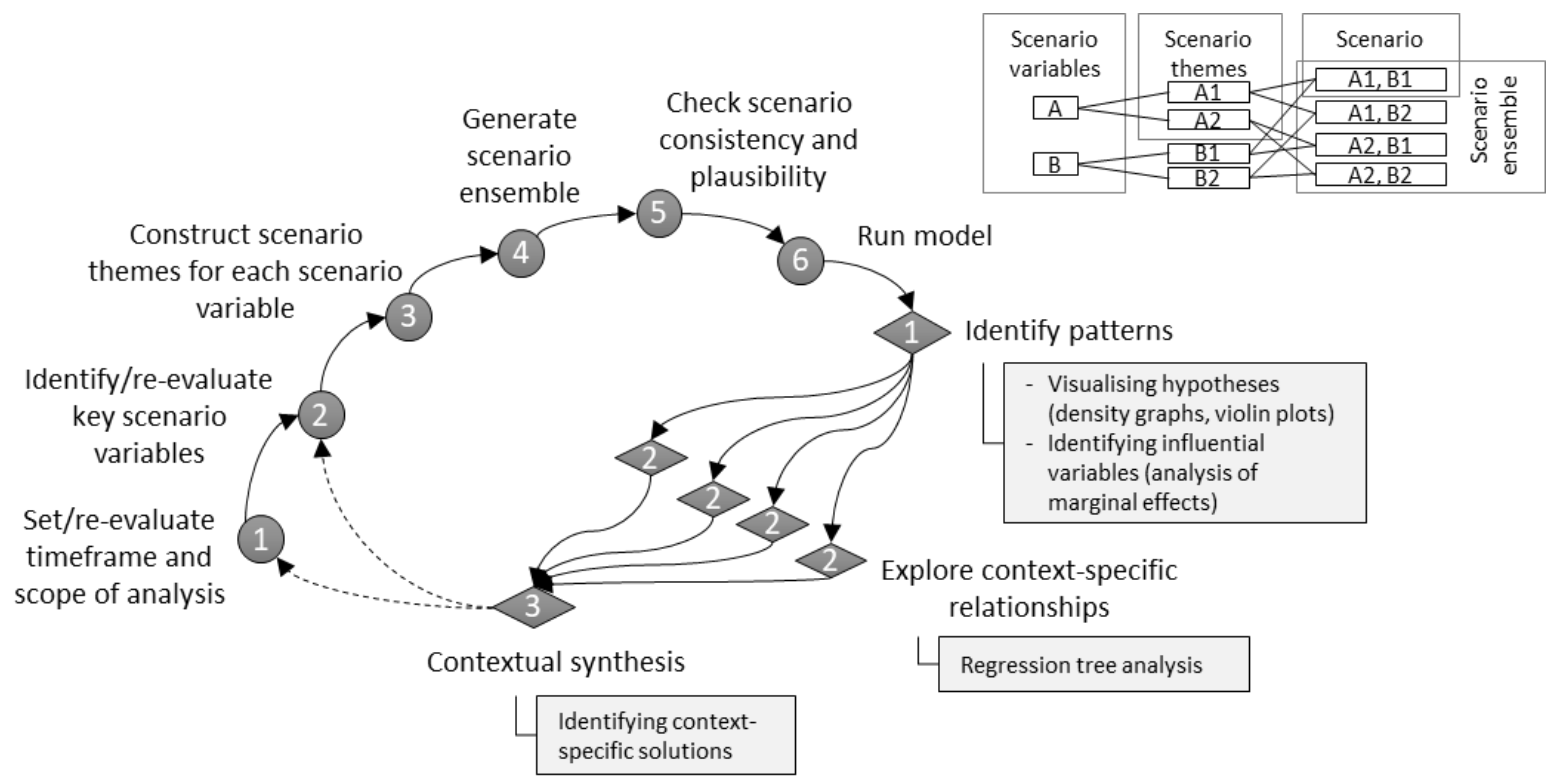

Figure 1: Scenario development (circle) and scenario analysis (diamond) processes. Definitions of various scenario terms are illustrated (top right), as well as practices and techniques used for exploratory scenario analysis (grey box). These processes are described in Sections 2.2.1-2.2.4. Dashed line indicates iteration.

\subsubsection{Scenario development}

During the scenario development phase we start by identifying the analysis timeframe and scope. In this case study, the emphasis is on medium-term questions relating to management options, within the context of uncertain climate futures and market prices for crops.

The second step is to select key scenario variables based on the analysis scope (i.e. the focal questions for the analysis). Here we use the term "scenario variable" to cover any variable that represents having either future system uncertainties that cannot be controlled (e.g. climate, market), uncertainties in model components and variables (e.g. hydrological modeling errors), or management options that can be employed to potentially change the outcomes (e.g. water saving practices).

The third step is to construct scenario themes for each variable. Here, scenario themes refer to states given to each scenario variable (Figure 1). For example, for the climate variable, there are different ways to construct scenario themes depending on the analysis scoping. The themes can be wet vs. dry climate scenarios, stable vs. highly variable climate scenarios, or current vs. future climate scenarios. In practice, the construction of themes allows us to identify explicit discrete, or a range of values for each scenario variable. A scenario is then formed by combining one theme from each scenario variable as inputs for a model run (Figure 1).

A scenario ensemble is then created to include the full collection of scenarios. In our case, we investigated 13 scenario variables ( 7 relating to system uncertainty and 6 relating to management/policy options), which generated an ensemble of 16,384 scenarios. The selection of scenario variables and scenario themes is summarized in Section 2.3 with details provided in Supplementary Material B. The selection of scenario variables and the construction of scenario themes often significantly influences the results of scenario analysis (see Section 4.2 for discussion).

At this point it is important also to check the consistency and plausibility of the scenarios (Schoemaker, 1995; Weimer-Jehle, 2006). Checking consistency for each scenario is not always possible, especially when the ensemble is large, as is in this case study. Here we undertook a qualitative assessment of extreme cases to identify inconsistent scenario ensembles (e.g. is it plausible to have a high adoption rate for spray irrigation in a wet climate?). It is also possible to program rules that automatically remove inconsistent scenarios. Here we found no inconsistent scenarios. 
The model is then run for each scenario within a scenario ensemble, resulting in multiple outputs in economic and environmental outcomes. These outputs are also aggregated, such as based on different weights to account for the value judgement held by the community in terms of the ensuing trade-offs between the multiple outcomes, as described in Section 2.1.

\subsubsection{Identifying patterns}

Step 1 of the analysis phase (Figure 1) involves identifying patterns in model results. At this stage the purpose of the scenario analysis is to explore the output space of scenarios, identify patterns or clusters if any, and investigate the main driver(s) of these patterns. Our experience suggests that sometimes management options may not initially seem to have significant impacts on outputs, especially when their impacts are masked by other drivers such as climate. Therefore, the patterns and causes thereof, if identified, can guide us to undertake more detailed context-specific analysis, from which the effectiveness of designing policy and/or research priorities may become more apparent.

We focus on three modeling practices that can be employed for pattern identification: 1) visualizing initial hypotheses, 2) identifying influential variables, and 3) visualizing new hypotheses informed by the influential variables. The initial hypotheses may be derived from general knowledge (e.g. climate is the main driver for the multivariate outputs) and/or past experiences (e.g. increasing water allocation will lead to significantly better results). Visualizing initial hypotheses is a useful approach for initial data exploration and testing those initial hypotheses. This is because visualization allows the use of intuition to explore the data and is sensitive to potential surprises in a way that some statistical methods are not (Fayyad et al., 2002). The outcome of this practice is that existing knowledge and experiences may be contested or confirmed, thereby motivating more in-depth analyses. Identifying influential variables determines which variables should be focused on, and those which can perhaps be ignored within an analysis. This is particularly beneficial when a large number of variables are involved - as is typical in an integrated assessment. Many statistical techniques are available for this identification. We calculated marginal effects of variables because of their ease of interpretation and use with our chosen scenario sampling method. The method is best understood by looking at results (see Section 3.1.2). The outcome of this modeling practice is to suggest new hypotheses informed by data analysis. This new hypothesis is then visualized for confirmation.

\subsubsection{Exploring context-specific relationships}

In Step 2 of scenario analysis (Figure 1), we explore the output space of the scenarios within a specific context, e.g. dry climate and high prices, and form new hypotheses about the opportunities and/or vulnerabilities of the system within that context. Here we focus on identifying how the variables are influencing outcomes. Many data mining and meta-modeling techniques can be useful for this modeling practice. In our case study, regression tree analyses (Hothorn et al., 2006) were used because some input data were categorical, although other methods can also be useful (see discussion in Section 4.1). Regression tree analysis is a statistical method for non-parametric regression and classification that has been widely used for ecological data (De'Ath \& Fabricius, 2000). We used the ctree() function in the party package in $R$ (Hothorn et al., 2006). This method selects the explanatory variable with the strongest association to the response variable, which is measured by a Bonferroniadjusted $p$-value. It then implements an optimal binary split in the selected explanatory variable if the $p$-value is less than a threshold (we used 0.005). For ease of presentation in this paper, we specified the maximum depth of the tree to be 3 levels. The implications of this stopping rule are discussed later.

In our case study we identified values of exploratory variables influencing performance. Two investigations were undertaken, the first selecting biophysical system variables only as exploratory variables and the second focusing on management options only. The regression tree algorithm selects system variables/management options based on their ability to classify outputs. It therefore identifies the combinations of system variables/management options, if any, that result in a range of significantly different performance, from good to bad. This therefore provides more diverse information than simply looking for the combination of exploratory variables that leads to the best result under the worst conditions, i.e. with a max-min optimization. 


\subsubsection{Contextual synthesis}

Finally in Step 3 of the analysis (Figure 1), the findings are reviewed and synthesized. In this step we first focus on identifying solutions that work well in each specific context identified earlier (e.g. a specific climate and market condition). The synthesis then allows us to take the learning from the context-specific solutions and form a new and aggregated "big picture" by bringing the pieces together. In our case, we explored the best combinations of management options to achieve overall outcomes under each different climate, crop market situation and value judgement spectrum, and then looked for similarities - are there common options that are favorable under most of the context situations? These new and aggregated insights are the foundation for reevaluation of analysis scoping and uncertainty, and the next iteration begins. This practice works well when the solution to a problem is likely to be sensitive to very different underlying conditions or assumptions about the future (e.g. the dry vs. wet climate). By focusing on the specific context first, one avoids trying to solve everything, but focus on parts that work well. The benefits of this practice are two-fold: on the one hand it gives common options that work well in most cases, promoting robust management. On the other hand, the identification of context-specific solutions supports adaptive management in that it provides potential for switching management practices if required, as a means of dealing with uncertainty.

\subsection{Selection of scenarios}

The variables for scenario analysis include potential key system variables in the model as well as management option variables (Table 1). Scenarios in system variables are associated with uncertainties relating to external and uncontrollable drivers of the environmental and economic outcomes and, just as importantly, limitations in our knowledge. Scenarios in management options relate to interventions that are plausible enough to warrant investigation; for example interventions either by water managers in terms of modifying water allocation rules, or by farmers in terms of improving irrigation water use efficiency and adoption of new technology.

Variables and corresponding themes were selected based on relevant literature (Roberts \& Marston, 2011; Rogers \& Ralph, 2010; Ticehurst \& Curtis, 2015) and the authors' and model developers' prior knowledge in the case study area. The variables and their values are further described in Supplementary Material B. Notably, some scenarios are qualitative, such as the requirements of flood duration and groundwater depths, which are represented by an index curve for each categorical expert opinion, and the conjunctive use options, which are defined by a set of rules for each option.

The number of values selected for scenario runs is largely limited by computational capacity to run the complex integrated model, as well as a trade-off between the number of variables we use to generate scenarios and the number of values for each variable. In our case study, a total of 13 variables were selected, generating 16,384 scenarios that took 5 days to run (with Intel Core i5-2400 $(3.1 \mathrm{GHz})$ and $8 \mathrm{~GB}$ RAM). After running the model, the outputs in farm profits, groundwater sustainability and ecological outcomes were each scaled between 0 and 1 based on their respective range, then weighted based on the four types of value judgements. This produced 65,536 outputs.

Note that, consistent with the fit-for-purpose emphasis of bricolage-style analyses, modeling decisions needed to balance what we wanted to test and what could be done considering computational capacity. In other circumstances, we would have further explored climate uncertainty (wet/dry) and gone beyond the four types of value judgements. Implications of the scenario selection are further explained in the Discussion. 
Table 1: Scenarios selected in the case study. Descriptions of and references for the integrated model and scenarios variables and values selected are further provided in Supplementary Material A and B, respectively.

\begin{tabular}{|c|c|c|c|}
\hline Scenario type & Spatial scale & Scenario variable & Scenario theme \\
\hline \multirow[t]{7}{*}{$\begin{array}{l}\text { Scenarios in } \\
\text { system } \\
\text { variables } \\
\text { (exogenous } \\
\text { uncertainties) }\end{array}$} & \multirow[t]{2}{*}{$\begin{array}{l}\text { Regional and } \\
\text { above }\end{array}$} & Climate & $\begin{array}{l}\text { - Dry: period represented by lowest historical } 10 \text {-year mean } \\
\text { annual rainfall } \\
\text { - Wet: period represented by highest historical } 10 \text {-year mean } \\
\text { annual rainfall }\end{array}$ \\
\hline & & $\begin{array}{l}\text { Crop market } \\
\text { conditions }\end{array}$ & $\begin{array}{l}\text { - Down: crop prices for all the crops drop } 20 \% \text { over } 10 \text {-year } \\
\text { period. } \\
\text { - Up: crop prices increase by } 20 \% \text { over } 10 \text {-year period. }\end{array}$ \\
\hline & \multirow[t]{2}{*}{ Catchment } & $\begin{array}{l}\text { Hydrological } \\
\text { modeling }\end{array}$ & $\begin{array}{l}\text { - } 50 \% \text { of modeled flow (overpredicted flow rate) } \\
\text { - } 150 \% \text { of modeled flow (underpredicted flow rate) }\end{array}$ \\
\hline & & $\begin{array}{l}\text { Hydrogeological } \\
\text { modeling }\end{array}$ & $\begin{array}{l}\text { - } 80 \% \text { of modeled groundwater level (shallower than } \\
\text { modeled) } \\
\text { - } 120 \% \text { of modeled groundwater level (deeper than modeled) }\end{array}$ \\
\hline & \multirow[t]{3}{*}{ River reach } & $\begin{array}{l}\text { Requirements of } \\
\text { flood duration }\end{array}$ & $\begin{array}{l}\text { - Roberts: Duration curve based on Roberts and Marston } \\
\text { (2011) } \\
\text { - Rogers: Duration curve based on Rogers and Ralph (2010) }\end{array}$ \\
\hline & & $\begin{array}{l}\text { Relative importance } \\
\text { of flood attributes }\end{array}$ & $\begin{array}{l}\text { - Best guess: weights of } 0.5,0.2 \text { and } 0.3 \text { for duration, timing } \\
\text { and inter-flood dry period } \\
\text { - Favour duration: weights of } 0.9,0.05 \text { and } 0.05 \text { for duration, } \\
\text { timing and inter-flood dry period }\end{array}$ \\
\hline & & $\begin{array}{l}\text { Requirements of } \\
\text { groundwater depth }\end{array}$ & $\begin{array}{l}\text { - Best guess: groundwater suitability curve with zero } \\
\text { suitability at } 12 \mathrm{~m} \text { below ground or more } \\
\text { - Deep roots: groundwater suitability curve with zero } \\
\text { suitability at } 15 \mathrm{~m} \text { below ground or more }\end{array}$ \\
\hline \multirow[t]{6}{*}{$\begin{array}{l}\text { Scenarios in } \\
\text { management } \\
\text { options (policy } \\
\text { levers) }\end{array}$} & \multirow[t]{3}{*}{ Catchment } & $\begin{array}{l}\text { Maximum surface } \\
\text { water allocation* }\end{array}$ & $\begin{array}{l}\text { - Restricted rate: maximum surface water allocation rate = } \\
0.5 \text { times current entitlement } \\
\text { - Generous rate: maximum surface water allocation rate = } 2 \\
\text { times current entitlement }\end{array}$ \\
\hline & & $\begin{array}{l}\text { Maximum } \\
\text { groundwater } \\
\text { allocation }\end{array}$ & $\begin{array}{l}\text { - Restricted rate: maximum groundwater allocation rate }=0.5 \\
\text { times current entitlement } \\
\text { - Generous rate: maximum groundwater allocation rate }=2 \\
\text { times current entitlement }\end{array}$ \\
\hline & & $\begin{array}{l}\text { Conjunctive use } \\
\text { options }\end{array}$ & $\begin{array}{l}\text { 1. By rain: groundwater allocation linearly related to rainfall } \\
\text { 2. Constant: groundwater allocation rate is constantly } 100 \% \\
\text { 3. Force fix: within a } 5 \text {-year cycle, when surface water } \\
\text { allocation is less than } 100 \% \text {, allow over-extraction of } \\
\text { groundwater but forcefully reduce groundwater allocation } \\
\text { in the } 5 \text { th year to maintain a long term average of } 100 \% \\
\text { allocation rate. } \\
\text { 4. Opportunistic and force fix: similar to 'force fix', except that } \\
\text { when surface water allocation is high (wet year), the } \\
\text { groundwater allocation will also be "fixed" to maintain a } \\
\text { long term average of } 100 \% \text { allocation rate. }\end{array}$ \\
\hline & \multirow[t]{3}{*}{ Farm } & $\begin{array}{l}\text { Flood irrigation } \\
\text { efficiency }\end{array}$ & $\begin{array}{l}\text { - } \operatorname{Min}=50 \% \text { water use efficiency } \\
\text { - } \operatorname{Max}=80 \% \text { water use efficiency }\end{array}$ \\
\hline & & $\begin{array}{l}\text { Spray irrigation } \\
\text { efficiency }\end{array}$ & $\begin{array}{l}\text { - } \operatorname{Min}=70 \% \text { water use efficiency } \\
\text { - } \operatorname{Max}=90 \% \text { water use efficiency }\end{array}$ \\
\hline & & $\begin{array}{l}\text { Adoption of spray } \\
\text { technology }\end{array}$ & $\begin{array}{l}\text { - } \operatorname{Min}=0.5 \% \text { adoption rate } \\
\text { - } \operatorname{Max}=16.9 \% \text { adoption rate }\end{array}$ \\
\hline
\end{tabular}

*: The actual annual allocation is calculated based on the level of annual rainfall relative to maximum annual rainfall, and the maximum allocation rates (Eq. 8 in Supplementary Material A). 


\section{Results and interpretation: insights from the analysis}

\subsection{Identifying patterns}

\subsubsection{Visualizing initial hypotheses}

In this case study, the initial hypotheses concern the effects of climate and water management options on model outputs. We tested these effects by visualizing the distributions of model outputs for dry and wet climate scenarios, and for different flow allocation options, using the violin and box plots. The plots were generated using the ggplot2 package in R (Wickham, 2009). The box plots show summary statistics and the violin plots show the density of the model output data at different values, which is especially useful when the data are multimodal.

In terms of the climate effect, the plots (Figure 2 ) indicate that mean annual profits within the sampled scenarios range from $\$ 1.4$ million to $\$ 4$ million but the differences across climates are not obvious, likely due to the relatively large proportion of dryland farming in the area. The standard deviation of annual profits also appears to be similar between the wet and dry climate. In contrast, climate seems to have significant impact on the outputs in groundwater, flow, mean annual suitability index for the maintenance of river red gum (RRG), and groundwater depth (Gw depth mean and $\min$ ).

In terms of the effect of maximum flow allocation, Figure 2 suggests it does not yield significantly different modeled outputs. Only small differences in model outputs are found between the two maximum flow allocation options. Similar results are also found for other management options. This is an indication that factors other than management options may dominate the effect of management.

At this point, it was clear that due to large uncertainties, neither climate scenarios nor management options alone can explain the differences in all model outputs. The attention was thus switched from testing of fixed initial hypotheses to exploring influential variables that will allow the formulation of new hypotheses.

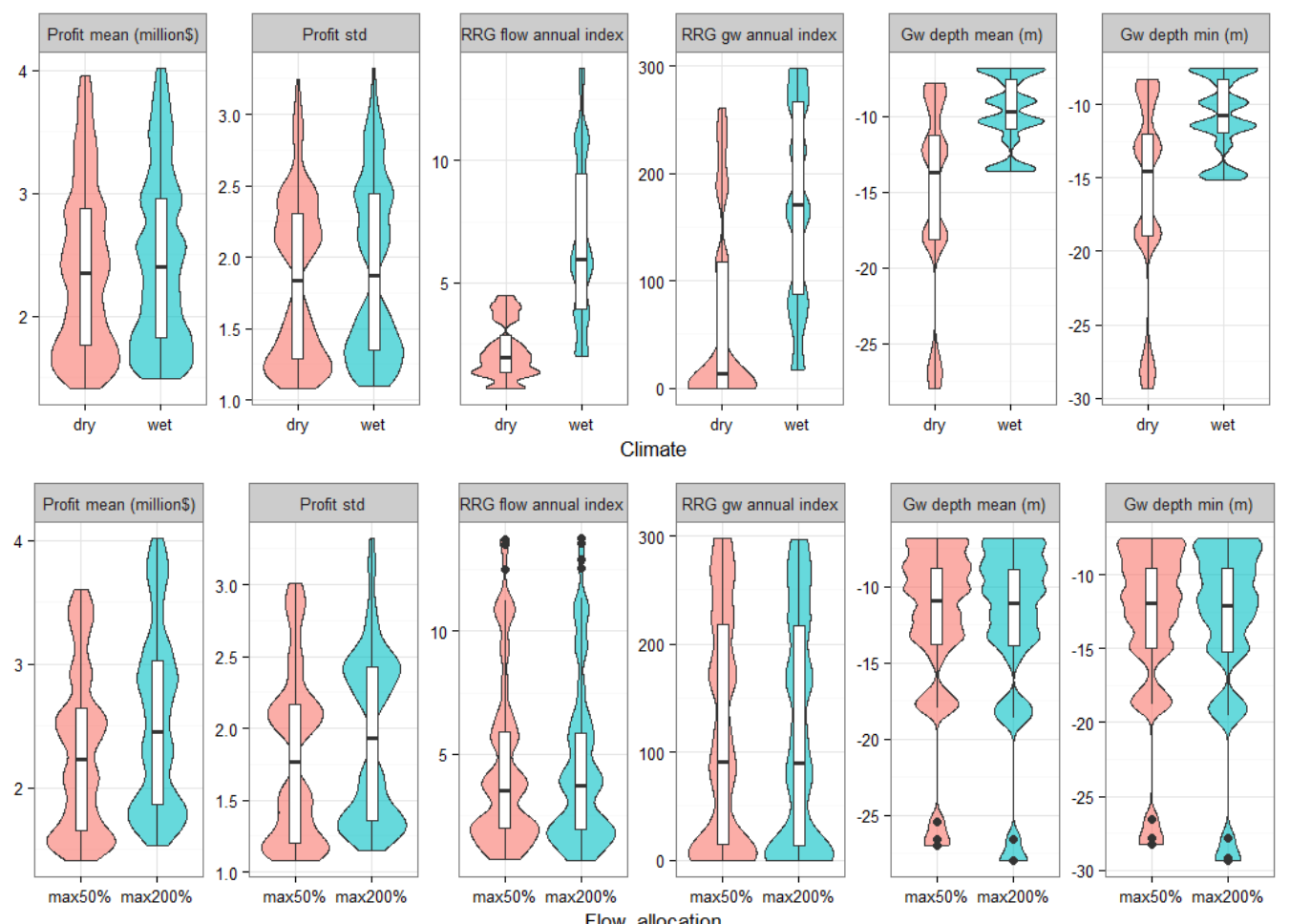

Figure 2: Violin and box plots of the six outputs under two climate conditions (top) and two maximum surface water allocation options (bottom). RRG: river red gum. 


\subsubsection{Identifying influential variables}

To clarify the effect of management and climate in the presence of external uncertainties, marginal effects were calculated. The scenarios form a full factorial sample, i.e. every combination of variables is present, so it is possible to calculate how an output changes in response to a single scenario variable (the marginal effect), keeping all else constant - and repeating this calculation for every combination of other scenario variables. The $\mathrm{R}$ code for the marginal effect analysis (and all other analysis in this paper) is freely available from Fu and Guillaume (2018).

Figure 3a shows the distribution of marginal effects of each scenario variable on the mean profit. For the conjunctive use options, it shows the difference between specific pairs of options. To identify influential variables for each different output, we calculate the mean marginal effect of each scenario variable, and express it as a percentage of the maximum (absolute) marginal effect, as shown in Figure $3 \mathrm{~b}$.
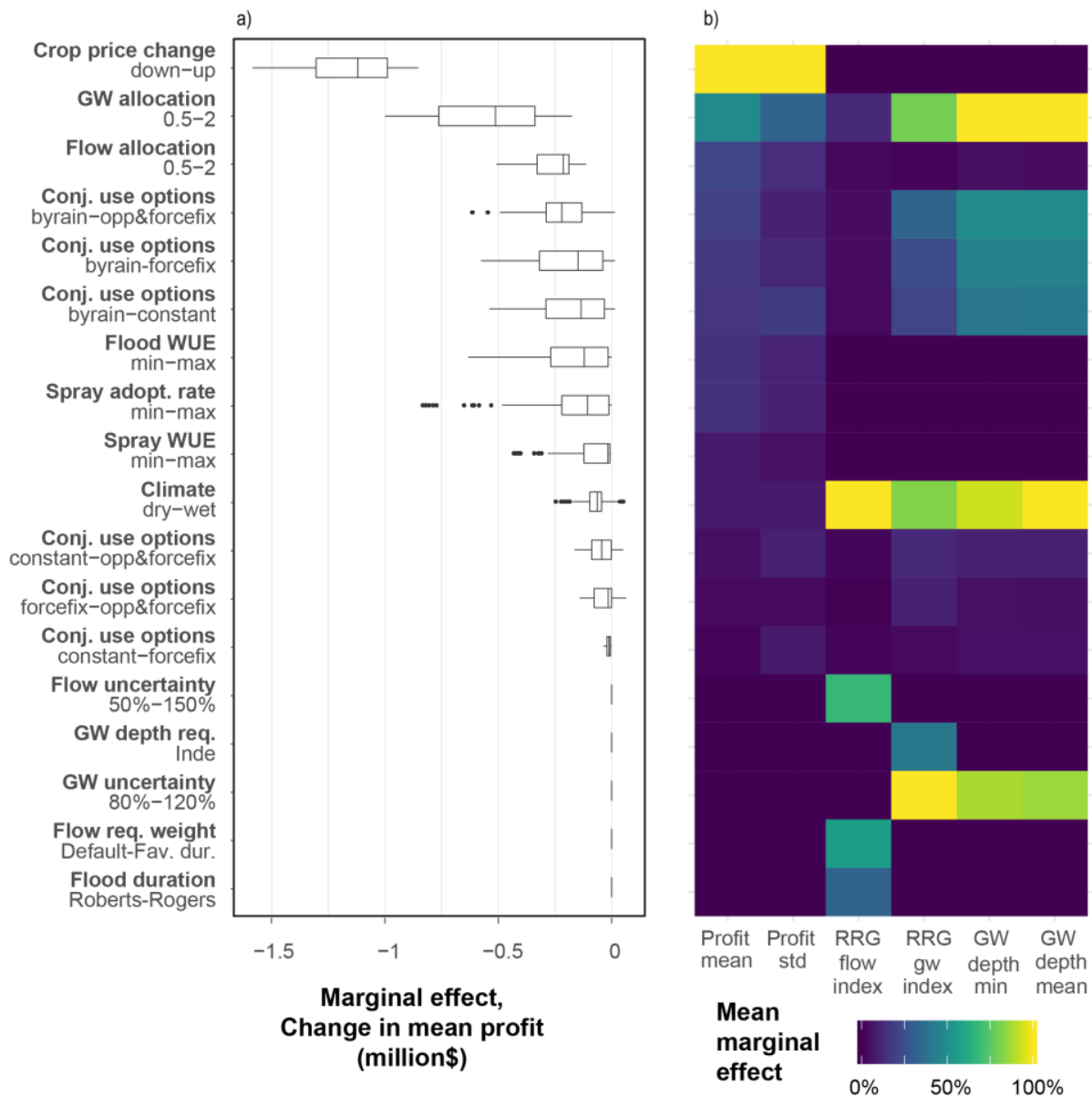

$\%$ of max for each output variable

Figure 3: a) Marginal effect of each scenario variable for model outputs in mean profit, and b) variable importance (average marginal effect) for all model outputs. The lighter the colour the more important the variable is in differentiating the corresponding output.

As one could expect, change in crop price has the largest effect in changing outputs in mean profit (i.e. it is the most influential variable), followed by groundwater and flow allocation (Figure 3a). Several variables do not influence mean profit, and therefore have zero marginal effect. The effect of climate seems less uncertain in this visualization. Whereas Figure 2 shows that the distributions of mean profit for dry and wet climate overlap substantially, we see here that dry climate does have lower profit than wet in most scenarios. This reduction in uncertainty is common after accounting for correlation between variables, here, by keeping all other variables constant, rather than capturing joint probability distributions (Reichert \& Borsuk, 2005). Looking at the raw data, it turns out that the exceptions are cases with low groundwater and flow allocations, and the opportunistic and force-fix conjunctive use option, which allows more water to be used in dry than in wet conditions. 
Over all six model outputs, climate and crop price change are the most influential variables (Figure 3b). Crop price change mainly impacts profits, while climate mainly impacts other outputs. Maximum groundwater allocation rate and groundwater model uncertainty also seem to be important for the groundwater related outputs. For river red gum flow suitability indices, the climate is most important, followed by uncertainty in the hydrology model.

Given that the focus of this paper is on bricolage, we should highlight here that the first version of the analysis instead used random forest variable importance measures (Jaxa-Rozen \& Kwakkel, 2018; Strobl et al., 2007). A reviewer then suggested that analysis of marginal effects is a more direct way of assessing variable importance, given a full factorial sample was available. A bricolage approach necessarily uses the methods that the analyst is aware of and has considered at that point in time. When the analyst becomes aware that a technique was overlooked, they should consider whether it is worthwhile (and still possible) to switch. In our case, switching methods allowed virtually the same variable importance visualization (Figure $3 \mathrm{~b}$ ) to be produced, with reasonable additional effort. But, the marginal effects method is easier to understand and interpret, as certain features of random forests were not needed (recursive partitioning and robustness to overfitting). While we switched methods, it is important to highlight that the bricolage was just as legitimate before the change as after. Legitimacy comes from defensible choices based on the available information rather than from using any supposedly universal "best" practices.

\subsubsection{Visualizing new hypotheses}

The above analysis suggested that the distributions of the scenario outputs for each climate-market (via crop price) situation should be significantly different, i.e. distinct patterns of scenario outputs can be observed within each climate-market context. Here we visualize this hypothesis for confirmation through distribution plots, and look for new hypotheses through the observation of patterns.

As shown in Figure 4a, in the "wet (climate) and (market) up" situation, most of the outputs receive above average (i.e. 0.5 ) values, with the exception of the standard deviation of profit, and river red gum flow suitability indices for the maintenance of river red gum. In the "dry and up" situation, farm mean profits are still high, but other outputs such as flow and groundwater indices for river red gum, and groundwater depth (mean and minimum) are all low. High uncertainty is identified for the groundwater index in this situation, indicating potential for further analysis. In the "dry and down" situation, all results are low, and similarly there is high uncertainty for the groundwater index. In the "wet and down" situation, groundwater sustainability obtains good outcomes, as well as the groundwater index, but the flow index outputs are mixed, with the possibility of both above and below average outcomes. As expected, farm profits are low in this scenario, driven by market price.

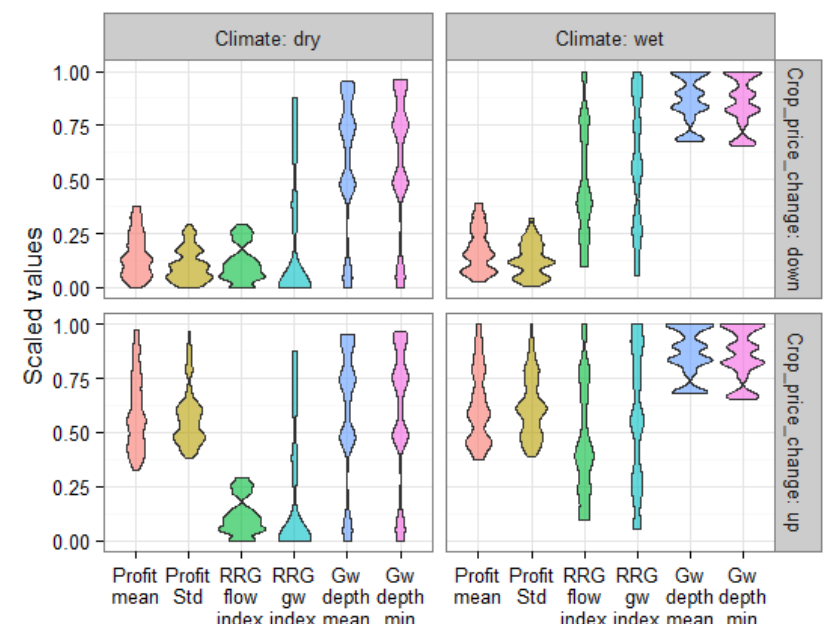

(a)
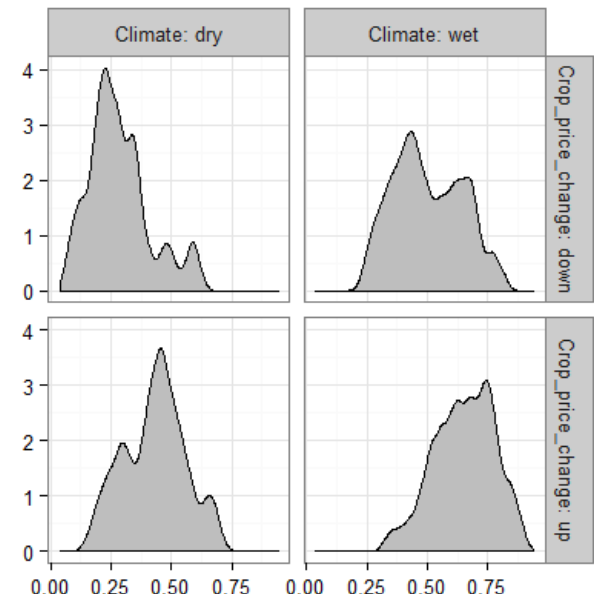

(b)

Figure 4: The violin plots (a) show four clusters of scenario outputs in profits (Profit mean, Profit Std), ecological outcome (RRG flow index, RRG gw index) and groundwater sustainability (Gw depth mean, Gw depth min), identified by climate and crop market. Note the values for each outcome indicator were scaled based on the ranges of that indicator. The density diagrams (b) show the weighted outcomes (including all four weighting options) for each climate and market combination. One set of scenario outputs (contains 6 output variables) in (a) yields four aggregated values (from four weighting options, Section 2.1). Thus (b) has four times the number of data points compared to (a). An aggregated value of 1 in (b) corresponds to the maximum value in all 6 output variables in (a). 
While the four clusters of plots are useful in exploring the distributions of multimodal data for multiple indicators, the information may still be seen as complex, especially as the number of indicators increases. This was resolved by aggregating the outputs. One set of scenario outputs produces four aggregated values based on four weighting options (Section 2.1). An aggregated value of 1 corresponds to the maximum value in all six scenario output variables.

The distributions of the aggregated outcomes are shown in Figure $4 \mathrm{~b}$. The results reinforce some of the messages conveyed earlier, but with informed simplicity (by reducing it to one dimensional data) without losing multidimensional information. From these distributions of aggregated values one can look for clusters of data that may reflect system vulnerability (indicated by lower aggregated results) or opportunity for improvement (indicated by higher aggregated results) under each climate-market context. For example, in dry climate and good market conditions, there are still opportunities to achieve above average overall outcomes (i.e. with aggregated values greater than 0.5 ). One question would be whether these above average outcomes can be achieved by interventions or whether they are mainly due to uncertainty in the system?

In summary, analyzing patterns has allowed us to generate meaningful context (in this case the climate-market clusters) and new questions to be answered in this context. In the case study, we identified two questions that require further investigation:

1) Which system variables contribute to the high uncertainty in groundwater suitability for the maintenance of river red gum? In particular, is it mainly due to uncertainty in groundwater modeling or uncertainty in ecological knowledge? This question was motivated by the high uncertainty in groundwater suitability index portrayed in Figure 4a. Answering this question can help prioritize research strategies for the region.

2) In dry climate and good market conditions, if one is at the center of the anthropocentrismpartnership-ecocentrism scale (i.e. equally weighting the different types of outputs), what management options can possibly be taken to achieve higher aggregated outcomes? This question was motivated by the potential opportunity to achieve above average overall outcomes identified in Figure $4 b$, and can be highly relevant to the development of adaptive management strategies.

We explore these two questions next. Note there are other questions that can be raised, such as how uncertainty in groundwater suitability index is driven by uncertainties in system and management variables. In practice, the questions and priorities that could be further investigated can be informed by engaging stakeholders, such that investigation into management opportunities or system vulnerabilities can be more targeted to local interest. Nevertheless, this bricolage-style analysis exemplifies the constructive decision-aiding approach (Tsoukiàs, 2008) whereby the problem formulation becomes part of the analysis outcomes.

\subsection{Exploring context-specific relationships}

\subsubsection{Uncertainty in the groundwater suitability index}

To investigate the first question raised in the previous step (Section 3.1.3), the regression tree analysis was used to investigate the effects of key variables on the groundwater suitability index outputs in the dry climate scenario. In this investigation, the groundwater suitability index was used as the dependent variable, and only system variables (as in Table 1) as explanatory variables. With management options excluded as explanatory variables in the analysis (but the datasets associated with management scenarios were still included in the analysis), we intentionally directed the analysis to focus on explaining groundwater suitability outputs using system variables only, thus answering the question of which source of system uncertainty is more important, given uncertainties in market and management options: i.e. groundwater modeling, or knowledge of groundwater depth requirements of river red gum.

The results show that, within the scenario samples, in a dry climate, groundwater uncertainty is the primary variable to split the dataset, followed by the ecological knowledge on groundwater depth requirement of river red gum (Figure 5). This indicates that the primary grouping of the groundwater suitability index depends on uncertainty in the prediction of groundwater depth, and that the uncertainty in ecological knowledge is secondary. The same tree structure was also found in the wet climate scenario (Figure 5). We also note that in the dry climate, when groundwater is actually assumed to be shallower than modeled (i.e. $80 \%$ ), there is still a 
high level of uncertainty in the groundwater suitability index (Nodes 3 and 4 in Figure 5). This indicates that other variables may be important. Further investigation (through further splitting Node 3, and adding management options as explanatory variables in the regression tree analysis) suggested that maximum groundwater allocation rate and conjunctive use options are the key management options to separate the groundwater index values into higher and lower values (not shown here).
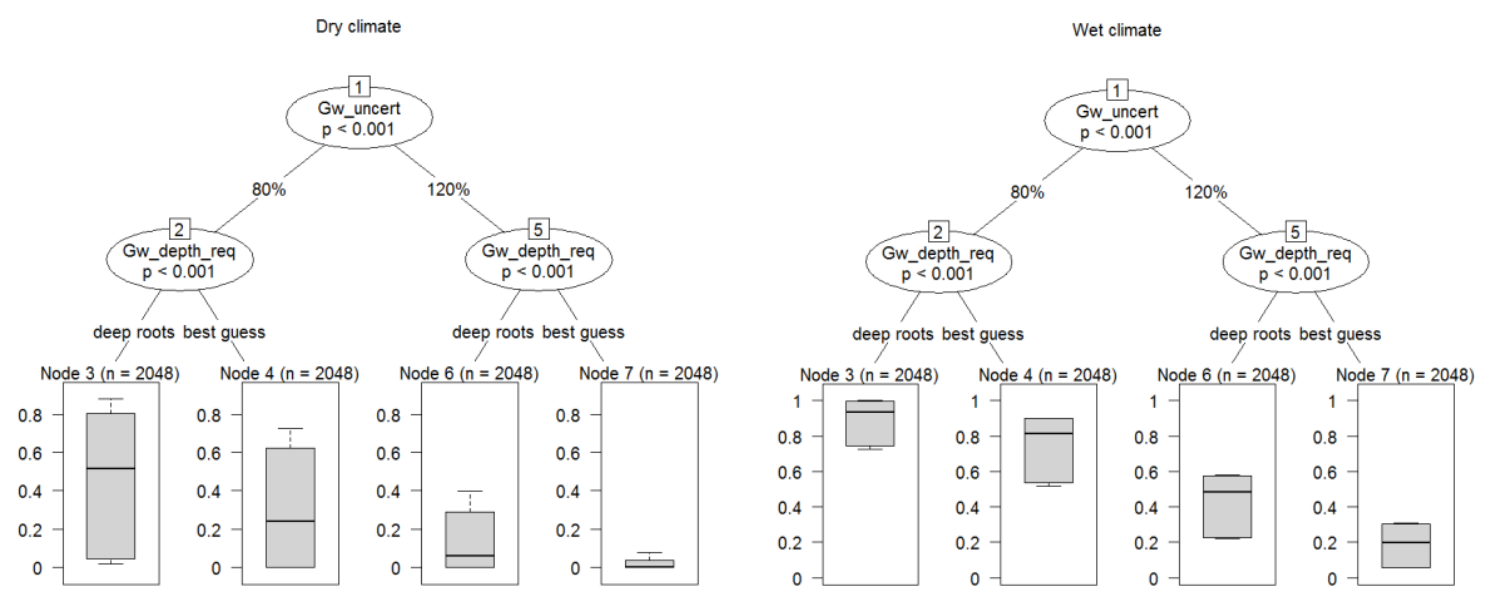

Figure 5: Regression tree showing the classification of groundwater suitability outcomes for river red gum for the dry climate scenario, with the wet climate for comparison. The terminal nodes are the classified outcomes displayed as box plots. This highlights the relative effect of gw_uncert and gw_depth_req. Gw_uncert refers to increases and decreases of the modeled groundwater depth by 20\%. Gw_depth_req refers to assumptions that river red gum can access groundwater at $12 \mathrm{~m}$ (best guess) or $15 \mathrm{~m}$ (deep roots). A $\mathrm{p}$-value of less than 0.001 indicates the binary split produces two significantly different distributions.

\subsubsection{Interventions for better overall outcomes}

Similarly, to investigate the second question raised in the previous step (Section 3.1.3), regression tree analysis was used to investigate what management options one can undertake to ensure better overall (equally weighted) outcomes are achieved in the dry climate and good market scenarios. In this case, the equally weighted output is the dependent variable, and all other management option variables (as listed in Table 1) are explanatory variables. Note that system variables are not included as explanatory variables, only as uncertain variables within the scenario ensemble. In doing so, one instructs the regression tree analysis to focus on relationships relating to management options, while still incorporating uncertainty introduced by both system variables and management options.

As shown in Figure 6, in dry climate and good market conditions, the tree is first split by maximum groundwater allocation rate, with a lower rate (50\%) resulting in better overall weighted outcomes than a higher rate $(200 \%)$. The left branch of the tree is then split by maximum (surface) flow allocation, and the right branch by conjunctive use options, indicating that flow allocation becomes most important in separating outcomes when the maximum groundwater allocation rate is low; while on the right side, conjunctive use options become important. Looking at the three levels of tree collectively, a combination of lower maximum groundwater allocation rate $(50 \%)$, higher maximum surface water allocation rate (200\%) and higher flood irrigation efficiency (80\%) can achieve better overall (equally weighted) outcomes (Node 4), given all other uncertainties investigated - including the adoption of other irrigation approaches or uncertainties in groundwater modeling and ecological knowledge. In contrast, higher maximum groundwater allocation (200\%), coupled with more relaxed conjunctive use options (constant, force fix or opportunistic and force fix) and low flood irrigation efficiency (50\%), yields the worst overall outcomes (Node 15), considering uncertainties in the system and other management variables.

One advantage of the regression tree analysis is that it identifies a range of option pathways and subsequent output distributions. This information can be valuable for deliberation with stakeholders because the "best" options may not always be desirable (e.g. due to limitations in governance or social factors). The approach offers a less computationally expensive method to weighing different policies than say the stochastic Pareto-optimal approach of Giuliani et al. (2014). The tree helps explore other possible option pathways. For example, if the 
option pathway to Node 4 is not desirable (e.g. one does not want to reduce maximum groundwater allocation rate), then the pathway to Node 11 (i.e. high maximum groundwater and flow allocation rates (both 200\%) coupled with conjunctive option based on rainfall) is also an attractive option. Note that if one relaxes the stopping rules for the regression tree analysis to allow for more than 3 levels, spray irrigation adoption rate and spray irrigation efficiency variables appear at levels 4 and 5 of the tree (not shown here). As a result, the box plots split further and the median values and ranges shift accordingly, such that additional pathway options can be identified - in this case involving higher water use efficiency technologies such as spray irrigation. However, spray irrigation alone cannot be effective as it relies on the conditions set by the variables identified at the higher levels of the regression tree.

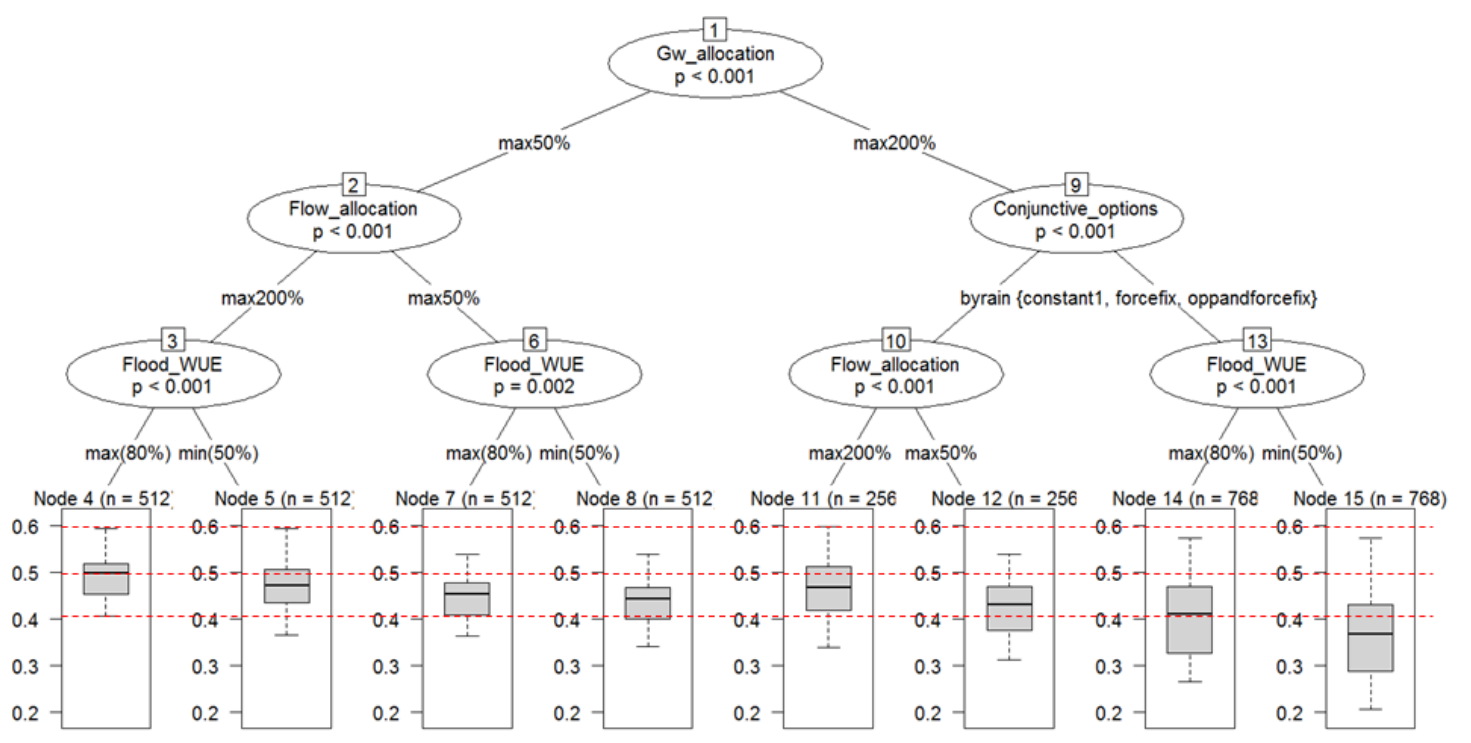

Figure 6: Regression tree showing the classification of equal weighted outcomes in dry climate and good market conditions. Horizontal dashed lines allow comparison of maximum, median and minimum of the first option (Node 4), compared to others.

Through the above explorative analysis, we came to the following three findings for the hypothetical case study.

1) Four distinct patterns emerged from scenario analysis of multiple output indicators. The formation of patterns is driven at the highest level by non-controllable variables - climate and market conditions.

2) In terms of ecological outcomes in groundwater suitability for the maintenance of river red gum, uncertainty in modeled groundwater depth has a significant impact on what outcomes can be achieved, while uncertainty in ecological knowledge in the groundwater requirement for river red gum is also important but appears to be secondary to groundwater modeling accuracy with the scenarios used here. This finding sets a research priority for the case study area if one is to reduce the uncertainty in estimating a groundwater suitability index in dry climate conditions.

3) We identified effective collective management options to achieve better overall outcomes in dry climate and good market conditions. Under equal weighting of objectives, this involves change to a combined groundwater and flow allocation policy coupled with a more efficient ( $80 \%$ efficiency) flood irrigation approach.

1) While these findings are useful, there is a need to further explore effective management options in other climate and market contexts, and with other weightings of outcomes in the value judgement spectrum.

\subsection{Contextual synthesis}

The purpose of this step (at bottom of Figure 1) is to evaluate and summarize a short-list of options to manage water in the case study area under a range of climate and market contexts. The aim was to look for similarities - are there common options that are favorable under most of the context situations? While other approaches could be used, effective management options are considered here to be those that lead to the highest median overall outcome, while being substantially different from other result ranges, as informed by regression tree 
analysis. They therefore highlight aspects of management that commonly lead to good performance, rather than identifying "best" management solutions directly.

As summarized in Table 2, the maximum groundwater and surface water allocation rates are the most commonly identified options, followed by high flood irrigation efficiency, particularly for a left and middle accent on the anthropocentrism-partnership-ecocentrism scale. In general, however, there is a conflict in the options chosen for maximum groundwater allocation rate, being between the equal weight and profit-focused groups and the ecology-focused and groundwater-focused groups. The former groups prefer a higher maximum groundwater allocation rate and the latter groups a lower maximum groundwater allocation rate. Commonalities are also found between those of differing value judgement. For example, equal weight, ecology-focused and groundwater-focused groups all prefer lower maximum groundwater and higher maximum flow allocation rates in dry climate and good market conditions. Spray irrigation efficiency and spray irrigation adoption are not as important for any of the climate-market contexts based on the maximum 3-level stopping rules for the regression tree. If more complex combinations are allowed (removing the maximum 3-level stopping rule), then the adoption of high flood irrigation efficiency is sometimes replaced by high spray irrigation adoption and efficiency, but may require the support of particular conjunctive use options (results not shown here).

Table 2: Identified best combination of management options to achieve overall outcomes under different climate (wet or dry), crop market situations (up or down) and value judgements.

\begin{tabular}{|c|c|c|c|c|c|c|c|}
\hline \multirow{3}{*}{$\begin{array}{l}\text { Equal } \\
\text { weight }\end{array}$} & \multirow[b]{2}{*}{ Dry } & \multicolumn{3}{|c|}{ Market up } & \multicolumn{3}{|c|}{ Market down } \\
\hline & & $50 \%$ & $200 \%+80 \%$ & & $50 \%$ & $200 \%+$ & $1-3$ \\
\hline & Wet & $200 \%$ & $200 \%+80 \%$ & & & $200 \%+$ & \\
\hline \multirow{2}{*}{$\begin{array}{l}\text { Profit- } \\
\text { focused }\end{array}$} & Dry & $200 \%$ & $200 \%+80 \%$ & & $200 \%+$ & $200 \%+$ & \\
\hline & Wet & $200 \%$ & $200 \%+80 \%$ & & $200 \%+$ & $+200 \%+$ & \\
\hline \multirow{2}{*}{$\begin{array}{l}\text { Ecology- } \\
\text { focused }\end{array}$} & Dry & $50 \%$ & $200 \%$ & & $50 \%$ & $+200 \%$ & \\
\hline & Wet & & $80 \%$ & & $50 \%$ & & \\
\hline \multirow{2}{*}{$\begin{array}{l}\text { Ground } \\
\text { water- } \\
\text { focused }\end{array}$} & Dry & $50 \%$ & $200 \%+$ & 1-3 & $50 \%$ & + & 1 \\
\hline & Wet & $50 \%$ & $200 \%$ & & $50 \%$ & & \\
\hline 50 or $200 \%$ & \multicolumn{4}{|c|}{ Maximum groundwater allocation (\%) } & 50 or $200 \%$ & \multicolumn{2}{|c|}{ Maximum flow allocation (\%) } \\
\hline 50 or $80 \%$ & \multicolumn{4}{|c|}{ Flood irrigation efficiency (\%) } & \multicolumn{3}{|c|}{ Conjunctive options } \\
\hline 70 or $90 \%$ & \multicolumn{4}{|c|}{ Spray irrigation efficiency } & 0.05 or $16.9 \%$ & \multicolumn{2}{|c|}{ Spray irrigation adoption rate } \\
\hline
\end{tabular}

At this point, we found that a maximum flow allocation rate of $200 \%$ is one of the most frequently identified options to achieve best possible outcomes under the tested climate and market situations. However, this was not apparent in the initial exploration (Figure 2) when the data were not analyzed for separate climate and market conditions. This phenomenon is illustrated conceptually in Figure 7. Initially, a management option may not seem an obvious choice in terms of achieving ecological and economic outcomes (as in A, i.e. the dots are widely spread depending on other situations). However, it is possible that the outcomes generated from that management option are the best within a specific context (circles in B). That is, within each context (in our case the climate-market situation), the outcomes (dots in B) generated

A

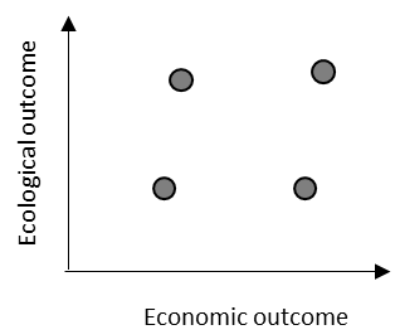

Figure 7: Diagram showing (A) ecological and economic outcomes (dot) of a management option; and (B) the outcomes in a specific context (circles). 
from that management option are the best. The pattern analysis allows the discovery of the critical context within which best management options can be identified. Visualization techniques such as facets (Kehrer \& Hauser, 2013) and small multiples (Tufte, 2001) are examples of contextual-based data analysis.

\section{Discussion}

\subsection{Contributions and limitations of practices}

This article has provided an illustrative bricolage-style exploratory scenario analysis of a case study in water allocation options that embodies uncertainty in future conditions and system variables. The method used could be applied to other socio-environmental modeling case studies, either in full or in part. This bricolage approach can be seen as an informal form of multi-method analysis. Six types of mixing approaches have been identified by Moallemi et al. (2018): isolationism, comparison, sequential, enrichment, interaction and integration. Bricolage requires some mixing, so does not fall into 'isolationism'. It does not result in 'integration' because it falls short of providing a new approach. However, other mixing approaches can be employed with the bricolage style analysis.

Our bricolage-style exploratory analysis can be seen as 'sequential', with the next step given by the previous step in the story. It consists of (1) a workflow that includes generic steps as illustrated in Figure 1, and (2) techniques used for these steps. The workflow of the analysis was adapted from the Adaptive Robust Design approach (Hamarat et al., 2013) and the Exploratory Modeling and Analysis methodology (Bankes et al., 2013; Kwakkel \& Pruyt, 2013). For example, the earlier stages of the workflow were adapted from the Adaptive Robust Design approach (Hamarat et al., 2013), with added components such as scenario consistency checking. The later stages in the Adaptive Robust Design workflow has strong emphasis on defining policy and use of optimization, which is not the purpose of our case study. Therefore, we modified the later stages of the workflow into more generalized steps to align with the Exploratory Modeling and Analysis methodology (Bankes et al., 2013; Kwakkel \& Pruyt, 2013), allowing different techniques to be used within these steps, without excluding those used in the Adaptive Robust Design approach (Hamarat et al., 2013).

The steps in scenario analysis involve visualizing hypotheses, identifying influential variables, separately identifying values of system variables and management options influencing outcomes, and identifying contextspecific solutions. We now reflect on how our use of methods in each of these steps in turn relates to existing work, and thus shed light on how bricolage can be achieved with other methods or techniques in the context of exploratory analysis.

Visualization is a common scientific tool, and is notably a focus of exploratory techniques like MORDM (Hadka et al., 2015; Kasprzyk et al., 2013). Testing of hypotheses is also an accepted part of scientific practice, and arguably occurs during the use of visualization (Kasprzyk et al., 2014). In this case, we emphasize specifically designing a visualization to check a hypothesis, notably to evaluate expected patterns of performance across subgroups. Visualization is a sufficiently large field that guidance is often required. Being specific about the purpose of visualization helps in its design. Admittedly, a strength of visualizations is that they can also achieve several purposes at once. For example, the exploratory iterative discovery method (Fu et al., 2015) aims to use visualizations that trigger updates to assumptions, interventions and management targets. We suggest that future work could similarly benefit from making explicit the transferable purpose of the visualizations they use. Identifying influential variables is also known as screening, a specific use of sensitivity analysis (Herman et al., 2015; Saltelli, Tarantola, et al., 2000). It is a common approach to narrow the set of variables considered, notably in parameter estimation. Thus, many sensitivity methods (Norton, 2015) can be applied here, depending on resources and model complexity. In this case, we demonstrate the utility of variable importance calculated using mean marginal effects, which is easy to interpret when using a full factorial sample with mostly two levels for each variable. The visualization using a gridded heat map was shown to effectively capture the effect of multidimensional output indicators and multiple sources of uncertainties.

Identifying the values of system variables affecting outcomes in this case was used similarly to a sensitivity or uncertainty analysis. Prioritization of sources of uncertainty could be achieved by identifying to which source an outcome is more sensitive, or by quantifying the uncertainty contributed by each. The use of regression trees has aspects of both, in that it uses the variables in the order of their effect on uncertainty, and communicates 
the resulting uncertainty. Additionally, we consider the effect of the uncertainties in the context of management rather than in isolation, recognizing that prioritization of future research may be influenced by uncertainty in future management.

Identifying management options resulting in different outcomes is related to robust optimization and scenario discovery. In principle the "best" outcome could be identified by optimization, and the combinations responsible for specific performance could be identified by scenario discovery (Bryant \& Lempert, 2010; Lempert et al., 2008). These approaches are central in many existing exploratory analysis such as scenario discovery (within which the Classification and Regression Tree (CART) method may also be employed) (Bryant \& Lempert, 2010; Lempert et al., 2008), Robust multi-objective optimization (Kwakkel et al., 2015), Info-Gap decision theory (BenHaim, 2006), and Robust Decision Making (Lempert \& Collins, 2007) require the specification of quantitative objective functions. The Adaptation tipping points (Kwadijk et al., 2010) method does not involve formal optimization, but still needs clear and quantified objectives. In cases where objectives are difficult to define, such as ours, there is value in taking a looser approach, emphasizing exploration of the scenario output space. Arguably, several of the above techniques can also be used in that way. Here, we used regression trees, providing an overview of solutions, yielding a more exploratory visualization that allows comparison of multiple pathways with similar performance. This overview and comparison feature is especially advantageous when the precise intentions of management are still subject to deliberations.

Identifying context-specific solutions is related to adaptive management. In this case, the context-specific solutions can be thought of as regime-specific. Climate and market conditions change over time, switching between regimes, and therefore allowing switching between solutions. In the context of water resources management, this idea can be seen in drought restrictions, temporarily reducing water consumption. In parts of Australia, it is already the practice to announce annually varying water allocations, usually starting conservatively and increasing through the season as inflows are received (Chiew et al., 2003). In this case, the focus is on medium-term strategic planning, looking for management options that appear to perform well in different contexts as part of combined strategies. It therefore provides a complementary approach to looking at regime-specific or regime-switching policies.

Our set of methodological practices and the techniques to implement them were selected specifically to be consistent with the idea of an exploratory scenario analysis. The underlying motivation was that uncertainty can be and has been used as an excuse to contest model results. The practices used emphasize general insights that the analyst can then follow up, and the techniques used can be explicitly tied back to the specific scenario ensemble generated. The interpretation of the results therefore depends on how the analyst's audience perceives that scenario ensemble. If the scenario ensemble were actually assumed to represent real uncertainty, then the results would become actual recommendations, for example, regarding design of management solutions and future research priorities. In this case, we do not know if scenarios actually do span the space of possibilities, and they probably do include implausible cases. The next step is therefore to test these hypotheses with stakeholder knowledge and design of future research, which is not covered in this paper. It is important to treat the results as just one input into decision making, and for the analyst to emphasize the assumptions on which the results depend when communicating them.

As a method alone, the particular steps documented in this study's workflow are not new; it is possible that people have gone through similar processes in their own work. However, we argue that it is a loss for the modeling community that there is no recognized way for the various workflows that are performed privately to be shared. Mechanisms to share workflows have been setup in other fields, e.g. the life science methods repository (https://www.protocols.io) and the methods oriented Elsevier journal MethodsX. These kinds of mechanisms, however, are better suited to experimental procedures than to exploratory scenario analyses. Experimental procedures are often time consuming and have physical requirements (e.g. materials and equipment) and well-defined outcomes. In contrast, exploratory scenario analyses are mainly limited by computing power and analyst knowledge, and are, by definition, exploratory, without a consistent outcome, such that describing full workflows is not an effective means of sharing know-how. In illustrating what a bricolage-style analysis can look like, we hope to raise awareness of the differences compared to sharing canonical methodologies, and the need for research publishing to tackle their unique characteristics.

One key difference between bricolage-based and traditional canonical recipes of exploratory analysis is that the latter are more easily evaluated by the reader - they are easily recognised by the community such that less 
effort is needed to check whether the recipe has been applied correctly. Such prior knowledge is not as easy to apply when evaluating bricolage-based methods, which may make them appear more difficult to follow and understand. A historical preference for developing and sticking to canonical, standardized methods is understandable. However, this bias needs to be fought in order to maintain the innovation necessary for successful exploratory analyses - a canonical recipe was just as valid the first time it was used, even though it was at the time new and unfamiliar. It is therefore important that peer review processes make the effort to help the author improve the understandability of their bricolage-based analysis, rather than simply encouraging them to switch to more familiar, easy to understand methods. Knowledge management technologies may provide assistance in future, notably regarding supporting traceability of the analysis and tracking provenance of data and assumptions (Gil et al., 2016; Zhang et al., 2017). These techniques are also likely to be useful in understanding the application of canonical recipes, especially for complicated situations, with large integrated models and many data inputs and outputs.

\subsection{Limitations of the case study and future work}

An important analysis choice we made in this case study was the selection of scenario variables and themes during the scenario development phase. The selection was largely informed by research questions and expert opinion, but a trade-off was made to balance what we wanted to test and what can be done considering computational capacity due to the long run time associated with the complex integrated model. In this case study, a total of 13 variables were selected. Except for the 'conjunctive use options' variable (which has four themes), all other variables contain two themes each. This seemingly small number of scenario variables and themes resulted in an ensemble of 16,384 scenarios $(212 \times 4)$, and about 5 days to complete model runs on a desktop. Adding just one additional scenario variable of 2 themes will double the run time. This is especially a challenge for integrated or complex models when run time is not trivial due to the inclusion of multiple components and their feedbacks. Computational efficiency could be improved to ease the restrictions on scenario selection by parallel and cloud computing (D’Angelo \& Marzolla, 2014; Hu et al., 2015). However, regardless of computational efficiency, there will always be an infinite number of scenarios that can be used for exploratory scenario analysis. It is fundamental in exploratory scenario analysis to apply appropriate strategies in the sampling of the scenario space, and to explicitly communicate the implications in understanding the results (Bankes, 1993).

In this case study, the motivation of the exploratory scenario analysis was to explore the implications of candidate management and policy options in the agricultural landscape given perceived uncertainties, so that water management and/or research priorities can be identified to improve environmental and socio-economic outcomes. As a result, all management-related variables in the integrated model were selected first. Then some variables relating to biophysical systems were selected based on what we thought the important sources of uncertainties could be in evaluating outcomes, which was informed by expert and stakeholder knowledge and evaluation of component models by the component modelers. In terms of model themes, we focused on the extreme cases when possible, intending to span a broad range of future scenarios, including some that would be considered unlikely, but not impossible. There are several implications of this scenario selection approach.

Firstly, there are many other variables that are either not included in the model (e.g. water carryover rules from season to season, water trading) or are included in the model but not tested (e.g. crop water requirements). Therefore, what we conclude from the exploratory exercise is only valid in the context where those untested variables remain unchanged. If some variables become a point of interest and/or expect to change in the future, then a new round of scenario development and exploratory scenario analysis should be undertaken.

Secondly, instead of testing individual parameters in the hydrology and groundwater models, we modified the flow and groundwater depth outputs uniformly to represent uncertainty in overestimating or underestimating flows and groundwater depth. This simplified approach to characterizing those uncertainties has the advantage of reducing the number of scenarios substantially and the amount of computation. Although uniformly increasing or decreasing groundwater depth can be acceptable due to the relatively low variation of groundwater depth in the system, this simplification can be problematic for flows. Better flow adjustment functions can be derived to differentiate the uncertainty in high and low flows.

Thirdly, only a limited number of themes were tested for the selected scenario variables. Some themes reflect contested categorical options (e.g. different opinions in the groundwater requirements of river red gum), and 
some capture extreme cases (e.g. the wettest and driest climate periods). We must stress that this sampling strategy strongly influenced the resulting distributions and regression tree analysis. The conclusions of exploratory scenario analysis only apply to the dataset comprised of these themes. Additional or different themes may (or may not) result in different patterns and relationships. In addition, the results are also influenced by the ranges selected for the variables; and thus they are the assumptions that need to be revisited with stakeholders when communicating the results. Given improved computational capacity, sampling quantitative scenario variables continuously would have allowed finer grained understanding of how assumptions influence results. Investigation into the potential impact of scenario sampling strategies on the results of scenario analysis is warranted in future studies. However, selection of alternative scenario sampling strategies still need to be fitfor-purpose, e.g. fitting the narratives or mental models of the stakeholders who may use the insights generated from the analysis for deliberations.

Fourthly, there are many factors that influence the path of an analysis (including scenario selection) that outcomes should probably always be considered path dependent (Lahtinen et al., 2017). Rather than aiming for an "eye of god" objectivity, an exploratory analysis takes the perspective that it is up to the analysts to judge whether they consider the underlying assumptions plausible. The analysis only shows the consequences of those assumptions. This is why we explicitly focused on a context in which an analyst is preparing to give expert advice - they have both necessary understanding of their audience, and the time and knowledge to evaluate the assumptions themselves.

In addition to scenario selection, the selection and formulation of indicators are also important in understanding the results of exploratory scenario analysis (Fu et al., 2017). In this case study, the indicators took the form of 10 -year annual summaries (e.g. mean annual profit), then scaled from 0 to 1 based on their ranges. In doing so, we assume that 1 ) other temporal variations (e.g. daily, monthly, seasonally, annually with shorter period of time) are not important in evaluating outcomes to inform water management and/or research priority; and 2) it is the relative outcomes (proportional to the best outcome) that are important and not absolute outcomes or other forms of formulation. If these assumptions are challenged, then new analysis should be undertaken using updated indicators.

As a proof of concept in integration and exploratory scenario analysis, the case study and integrated model provide a useful platform in that they capture some of the key elements to address water management issues in agricultural landscapes, namely the inclusion of interconnected hydrology and groundwater systems and their connections with farm systems and riverine ecosystems. Valuable insights (e.g. effective combination of management options in different contexts) were gained through exploratory scenario analysis that could not be obtained without the integration framework. We must stress that, like any other studies attaining insights (as opposed to obtaining objective results), the outcomes are path dependent (Lahtinen et al., 2017). In a bricolage context, the analyst has deliberately selected particular techniques because they were easy to apply and reason with. After the analysis, it may be possible to reflect and find another technique that supports, contrasts or complements the conclusions, but it is not possible to go back in time, only to draw lessons for the future. This highlights the important role of the analyst's background in shaping a bricolage-style analysis. While in principle, a comparison with competing methods can demonstrate the value add of an analysis, the very act of doing so would change the bricolage context. Admittedly, comparison could still be made by trying to take differences in context into account, but this is beyond the scope of this study.

\section{Conclusion}

Exploratory modeling and scenario analysis are useful tools to analyze policy and management options that are characterized by deep uncertainties. In this paper, we used a case study to demonstrate how a bricolage-style exploratory scenario analysis can be applied using modeling practices and techniques. The case study is representative of a typical agricultural landscape in the Murray-Darling Basin in Australia, and involves the integration of hydrology, groundwater, ecology, policy and farm systems. Three high level analysis practices were used: identifying patterns, exploring context-specific relationships, and contextual synthesis. These practices were implemented using a range of methods: visualization, regression tree analysis and analysis of marginal effects. 
Through the exploratory scenario analysis, it was demonstrated how new hypotheses and insights were generated and evolved. We found that the environmental and economic outcomes were not dominated by any single variable, and that the effectiveness of management options was not apparent. Through identifying patterns we found climate and market conditions as the main drivers of these outcomes. Then through exploring context-specific relationships we discovered that groundwater uncertainty is more important than ecological knowledge for groundwater requirement of river red gum species, and that a certain combination of water allocation rules and flood irrigation efficiency is important in achieving better outcomes under dry climate and good market conditions. Through contextual synthesis we found effective combinations of management options under each of the different climate, market and value judgement conditions, and observed that flow allocation is the common effective management option across all situations.

The bricolage approach exemplifies the value of creating "stories" or narratives through scenario analyses, rather than aiming to provide definitive answers or optima when uncertainty is rife. This allows end users to make the final decision as to what underlying assumptions should be accepted, and whether uncertainties have been sufficiently explored. In discussing the usefulness of exploratory scenario analysis and the use of various modeling practices, we emphasized the importance of stating the assumptions of the modeling and analysis, and how these assumptions provided context under which the conclusions of the exploratory scenario analysis are valid.

The perspective presented in this paper was echoed by reviewer comments, that they had performed similar exploratory analyses, that they would have used a different set of methods, that the workflow is not sufficiently distinct to be published as a "new method", and that it is difficult for this kind of analysis to be published other than as a site-specific case study. Bricolage presents a paradox: everybody does it and everybody finds it useful, but we force ourselves to only publish transferable "methods", such that know-how about how to do bricolage is gained mainly by learning by doing, rather than by learning from others. While we are far from having a solution to this problem, this article aims to show that it is a problem worth solving.

\section{Acknowledgements}

This work was funded by the Australian National Centre for Groundwater Research and Training (NCGRT), and the MDBA-NCGRT Partnership. Joseph Guillaume was supported by the Academy of Finland WASCO water scarcity atlas project (grant number 305471). We would like to thank Dr. Carmel Pollino and four anonymous reviewers for their constructive comments on the draft manuscript.

\section{References}

Badham, J., Elsawah, S., Guillaume, J.H.A., Hamilton, S.H., Hunt, R.J., Jakeman, A.J., Pierce, S.A., Snow, V.O., Babbar-Sebens, M., Fu, B., Gober, P., Hill, M.C., Iwanaga, T., Loucks, D.P., Merritt, W.S., Peckham, S.D., Richmond, A.K., Zare, F., Ames, D., \& Bammer. G. (2019). Effective modeling for Integrated Water Resource Management: a guide to contextual practices by phases and steps and future opportunities. Environmental Modelling \& Software, 116, 40-56. doi.org/10.1016/j.envsoft.2019.02.013.

Bankes, S. (1993). Exploratory Modeling for Policy Analysis. Operations Research, 41(3), 435-449. doi:10.1287/opre.41.3.435

Bankes, S., Walker, W. E., \& Kwakkel, J. H. (2013). Exploratory modeling and analysis. In Encyclopedia of operations research and management science (pp. 532-537): Springer.

Bankes, S. C. (2002). Tools and techniques for developing policies for complex and uncertain systems. Proceedings of the National Academy of Sciences, 99(suppl 3), 7263-7266. doi:10.1073/pnas.092081399

Beck, M. B. (1987). Water quality modeling: a review of the analysis of uncertainty. Water Resources Research, 23(8), 13931442. doi:10.1029/WR023i008p01393

Beh, E. H. Y., Maier, H. R., \& Dandy, G. C. (2015). Adaptive, multiobjective optimal sequencing approach for urban water supply augmentation under deep uncertainty. Water Resources Research, 51(3), 1529-1551. doi:10.1002/2014WR016254

Ben-Haim, Y. (2006). Info-Gap Decision Theory (Second Edition). Oxford: Academic Press.

Bennett, N. D., Croke, B. F. W., Guariso, G., Guillaume, J. H. A., Hamilton, S. H., Jakeman, A. J.,Marsili-Libelli, S., Newham, L.T.H., Norton, J.P., Perrin, C., Pierce, S.A., Robson, B., Seppelt, R., Voinov, A.A., Fath, B., \& Andreassian, V. (2013). Characterising performance of environmental models. Environmental Modelling \& Software, 40, 1-20. doi:10.1016/j.envsoft.2012.09.011 
Blakers, R., Croke, B., \& Jakeman, A. (2011). The influence of model simplicity on uncertainty in the context of surfacegroundwater modelling and integrated assessment. Paper presented at the 19th International Congress on Modelling and Simulation, Perth, Australia.

Brown, C., Ghile, Y., Laverty, M., \& Li, K. (2012). Decision scaling: Linking bottom-up vulnerability analysis with climate projections in the water sector. Water Resources Research, 48(9), n/a-n/a. doi:10.1029/2011WR011212

Bryant, B. P. (2014). sdtoolkit: Scenario Discovery Tools to Support Robust Decision Making (v2.33-1). Retrieved from cran.rproject.org/web/packages/sdtoolkit/index.html

Bryant, B. P., \& Lempert, R. J. (2010). Thinking inside the box: A participatory, computer-assisted approach to scenario discovery. Technological Forecasting and Social Change, 77(1), 34-49. doi:10.1016/j.techfore.2009.08.002

Buurman, J., \& Babovic, V. (2016). Adaptation Pathways and Real Options Analysis: An approach to deep uncertainty in climate change adaptation policies. Policy and Society, 35(2), 137-150. doi:10.1016/j.polsoc.2016.05.002

Chiew, F. H. S., Zhou, S. L., \& McMahon, T. A. (2003). Use of seasonal streamflow forecasts in water resources management. Journal of Hydrology, 270(1-2), 135-144. doi:10.1016/S0022-1694(02)00292-5

Croke, B., Ticehurst, J. L., Letcher, R., Norton, J., Newham, L., \& Jakeman, A. (2007). Integrated assessment of water resources: Australian experiences. Water Resources Management, 21(1), 351-373. doi:10.1007/s11269-006-9057-8

Croke, B. F., \& Jakeman, A. J. (2004). A catchment moisture deficit module for the IHACRES rainfall-runoff model. Environmental Modelling \& Software, 19(1), 1-5. doi:10.1016/j.envsoft.2003.09.001

D’Angelo, G., \& Marzolla, M. (2014). New trends in parallel and distributed simulation: From many-cores to Cloud Computing. Simulation Modelling Practice and Theory, 49, 320-335. doi:10.1016/j.simpat.2014.06.007

Daggupati, P., Pai, N., Ale, S., Douglas-Mankin, K. R., Zeckoski, R. W., Jeong, J., . . Youssef, M. A. (2015). A recommended calibration and validation strategy for hydrologic and water quality models. Transactions of the ASABE, 58(6), 17051719. doi:10.13031/trans.58.10712

De'Ath, G., \& Fabricius, K. E. (2000). Classification and regression trees: a powerful yet simple technique for ecological data analysis. Ecology, 81, 3178-3192. doi:10.1890/0012-9658(2000)081[3178:CARTAP]2.0.CO

Fayyad, U. M., Wierse, A., \& Grinstein, G. G. (2002). Information visualization in data mining and knowledge discovery: Morgan Kaufmann.

Fu, B., Dyer, F., Kravchenko, A., Dyack, B., Merritt, W., \& Scarpa, R. (2017). A note on communicating environmental change for non-market valuation. Ecological Indicators, 72, 165-172. doi:10.1016/j.ecolind.2016.08.018

Fu, B., \& Guillaume, J. (2018). A Bricolage Style Exploratory Scenario Analysis to Manage Uncertainty - Analysis Code and Data (Version v1.0). Retrieved from http://doi.org/10.5281/zenodo.1465093

Fu, B., \& Guillaume, J. H. (2014). Assessing certainty and uncertainty in riparian habitat suitability models by identifying parameters with extreme outputs. Environmental Modelling \& Software, 60, 277-289. doi:10.1016/j.envsoft.2014.06.015

Fu, B., Guillaume, J. H. A., \& Jakeman, A. J. (2015). An iterative method for discovering feasible management interventions and targets conjointly using uncertainty visualizations. Environmental Modelling \& Software, 71, 159-173. doi:10.1016/j.envsoft.2015.05.017

Gersonius, B., Ashley, R., Jeuken, A., Pathinara, A., \& Zevenbergen, C. (2015). Accounting for uncertainty and flexibility in flood risk management: comparing $\mathrm{R}$ eal-I $\mathrm{n}-\mathrm{O}$ ptions optimisation and $\mathrm{A}$ daptation $\mathrm{T}$ ipping $\mathrm{P}$ oints. Journal of Flood Risk Management, 8(2), 135-144.

Gil, Y., David, C. H., Demir, I., Essawy, B. T., Fulweiler, R. W., Goodall, J. L., . . Yu, X. (2016). Toward the Geoscience Paper of the Future: Best practices for documenting and sharing research from data to software to provenance. Earth and Space Science, 3(10), 388-415. doi:doi:10.1002/2015EA000136

Giuliani, M., \& Castelletti, A. (2016). Is robustness really robust? How different definitions of robustness impact decisionmaking under climate change. Climatic Change, 135(3-4), 409-424. doi:10.1007/s10584-015-1586-9

Giuliani, M., Herman, J., Castelletti, A., \& Reed, P. (2014). Many-objective reservoir policy identification and refinement to reduce policy inertia and myopia in water management. Water Resources Research, 50(4), 3355-3377. doi:10.1002/2013WR014700

Guillaume, J. H. A., Arshad, M., Jakeman, A. J., Jalava, M., \& Kummu, M. (2016). Robust discrimination between uncertain management alternatives by iterative reflection on crossover point scenarios: Principles, design and implementations. Environmental Modelling \& Software, 83, 326-343. doi:10.1016/j.envsoft.2016.04.005

Guillaume, J. H. A., Kummu, M., Räsänen, T. A., \& Jakeman, A. J. (2015). Prediction under uncertainty as a boundary problem: A general formulation using Iterative Closed Question Modelling. Environmental Modelling \& Software, 70, 97-112. doi:10.1016/j.envsoft.2015.04.004

Guzman, J. A., Shirmohammadi, A., Sadeghi, A. M., Wang, X., Chu, M. L., Jha, M. K., . . Hernandez, J. E. (2015). Uncertainty considerations in calibration and validation of hydrologic and water quality models. Transactions of the ASABE, 58(6), 1745-1762. doi:10.13031/trans.58.10710

Haasnoot, M., van Deursen, W. P. A., Guillaume, J. H. A., Kwakkel, J. H., van Beek, E., \& Middelkoop, H. (2014). Fit for purpose? Building and evaluating a fast, integrated model for exploring water policy pathways. Environmental Modelling \& Software, 60, 99-120. doi:10.1016/j.envsoft.2014.05.020

Hadka, D. (2016). High Performance Computing with the MOEA Framework and Ignite: CreateSpace Independent Publishing Platform.

Hadka, D. (2019). Project Platypus - A Collection of Libraries for Optimization, Data Analysis, and Decision Making. Retrieved from https://github.com/Project-Platypus 
Hadka, D., Herman, J., Reed, P., \& Keller, K. (2015). An open source framework for many-objective robust decision making. Environmental Modelling \& Software, 74, 114-129. doi:10.1016/j.envsoft.2015.07.014

Hall, J. W., Lempert, R. J., Keller, K., Hackbarth, A., Mijere, C., \& McInerney, D. J. (2012). Robust Climate Policies Under Uncertainty: A Comparison of Robust Decision Making and Info-Gap Methods. Risk Analysis, 32(10), 1657-1672. doi:10.1111/j.1539-6924.2012.01802.x

Hamarat, C., Kwakkel, J. H., \& Pruyt, E. (2013). Adaptive robust design under deep uncertainty. Technological Forecasting and Social Change, 80(3), 408-418. doi:10.1016/j.techfore.2012.10.004

Herman, J., Reed, P., Zeff, H., \& Characklis, G. (2015). How Should Robustness Be Defined for Water Systems Planning under Change? Journal of Water Resources Planning and Management, 04015012. doi:10.1061/(ASCE)WR.19435452.0000509

Hodges, J. S. (1991). Six (or so) things you can do with a bad model. Operations Research, 39(3), 355-365. doi:10.1287/opre.39.3.355

Hodges, J. S., \& Dewar, J. A. (1992). Is it you or your model talking?: A framework for model validation: Rand Santa Monica, CA.

Hothorn, T., Hornik, K., \& Zeileis, A. (2006). Unbiased recursive partitioning: A conditional inference framework. Journal of Computational and Graphical statistics, 15(3), 651-674. doi:10.1198/106186006X133933

Hu, Y., Garcia-Cabrejo, O., Cai, X., Valocchi, A. J., \& DuPont, B. (2015). Global sensitivity analysis for large-scale sociohydrological models using Hadoop. Environmental Modelling \& Software, 73, 231-243. doi:10.1016/j.envsoft.2015.08.015

Ivkovic, K., Croke, B., Letcher, R., \& Evans, W. (2005). The development of a simple model to investigate the impact of groundwater extraction on river flows in the Namoi catchment, NSW, Australia. Paper presented at the Proceedings of New Zealand Hydrological Society-IAH-NSSSS Conference 2005.

Jakeman, A., \& Hornberger, G. (1993). How much complexity is warranted in a rainfall-runoff model? Water Resources Research, 29(8), 2637-2649. doi:10.1029/93WR00877

Jakeman, A., Littlewood, I., \& Whitehead, P. (1990). Computation of the instantaneous unit hydrograph and identifiable component flows with application to two small upland catchments. Journal of Hydrology, 117(1-4), 275-300. doi:10.1016/0022-1694(90)90097-H

Jaxa-Rozen, M., \& Kwakkel, J. H. (2018). PyNetLogo: Linking NetLogo with Python. Journal of Artificial Societies and Social Simulation, 21(2), 4. doi:10.18564/jasss.3668

Kasprzyk, J., Guillaume, J., Kollat, J., \& Danilo, C. (2014, 2014). Hypothesis Testing for Management: Evolving and Answering Closed Questions Using Multiobjective Visualization. Paper presented at the International Congress on Environmental Modelling and Software, San Diego, California, USA.

Kasprzyk, J. R., Nataraj, S., Reed, P. M., \& Lempert, R. J. (2013). Many objective robust decision making for complex environmental systems undergoing change. Environmental Modelling \& Software, 42, 55-71. doi:10.1016/j.envsoft.2012.12.007

Kehrer, J., \& Hauser, H. (2013). Visualization and Visual Analysis of Multifaceted Scientific Data: A Survey. IEEE Transactions on Visualization and Computer Graphics, 19(3), 495-513. doi:10.1109/TVCG.2012.110

Kincheloe, J. L. (2001). Describing the Bricolage: Conceptualizing a New Rigor in Qualitative Research. Qualitative inquiry, 7(6), 679-692. doi:10.1177/107780040100700601

Kincheloe, J. L. (2005). On to the next level: Continuing the conceptualization of the bricolage. Qualitative inquiry, 11(3), 323350. doi:10.1177/1077800405275056

Kwadijk, J. C., Haasnoot, M., Mulder, J. P., Hoogvliet, M., Jeuken, A., van der Krogt, R. A., . . van Waveren, H. (2010). Using adaptation tipping points to prepare for climate change and sea level rise: a case study in the Netherlands. Wiley Interdisciplinary Reviews: Climate Change, 1(5), 729-740. doi:10.1002/wcc.64

Kwakkel, J. H. (2017). The Exploratory Modeling Workbench: An open source toolkit for exploratory modeling, scenario discovery, and (multi-objective) robust decision making. Environmental Modelling \& Software, 96, 239-250. doi:10.1016/j.envsoft.2017.06.054

Kwakkel, J. H., Eker, S., \& Pruyt, E. (2016). How Robust is a Robust Policy? Comparing Alternative Robustness Metrics for Robust Decision-Making. In M. Doumpos, C. Zopounidis, \& E. Grigoroudis (Eds.), Robustness Analysis in Decision Aiding, Optimization, and Analytics (pp. 221-237). Cham: Springer International Publishing.

Kwakkel, J. H., \& Haasnoot, M. (2019). Supporting DMDU: A taxonomy of approaches and tools. In Decision Making under Deep Uncertainty (pp. 355-374): Springer.

Kwakkel, J. H., Haasnoot, M., \& Walker, W. E. (2015). Developing dynamic adaptive policy pathways: a computer-assisted approach for developing adaptive strategies for a deeply uncertain world. Climatic Change, 132(3), 373-386. doi:10.1007/s10584-014-1210-4

Kwakkel, J. H., Haasnoot, M., \& Walker, W. E. (2016). Comparing robust decision-making and dynamic adaptive policy pathways for model-based decision support under deep uncertainty. Environmental Modelling \& Software, 86, 168183. doi:10.1016/j.envsoft.2016.09.017

Kwakkel, J. H., \& Pruyt, E. (2013). Exploratory Modeling and Analysis, an approach for model-based foresight under deep uncertainty. Technological Forecasting and Social Change, 80(3), 419-431. doi:10.1016/j.techfore.2012.10.005

Lahtinen, T. J., Guillaume, J. H., \& Hämäläinen, R. P. (2017). Why pay attention to paths in the practice of environmental modelling? Environmental Modelling \& Software, 92, 74-81. doi:10.1016/j.envsoft.2017.02.019 
Landry, M., Banville, C., \& Oral, M. (1996). Model legitimisation in operational research. European Journal of Operational Research, 92(3), 443-457. doi:10.1016/0377-2217(96)00003-3

Lempert, R. J. (2002). A new decision sciences for complex systems. Proceedings of the National Academy of Sciences, 99(suppl 3), 7309-7313. doi:10.1073/pnas.082081699

Lempert, R. J., Bryant, B. P., \& Bankes, S. C. (2008). Comparing algorithms for scenario discovery. RAND, Santa Monica, CA.

Lempert, R. J., \& Collins, M. T. (2007). Managing the risk of uncertain threshold responses: comparison of robust, optimum, and precautionary approaches. Risk Analysis, 27(4), 1009-1026. doi:10.1111/j.1539-6924.2007.00940.x

Lempert, R. J., Popper, S. W., \& Bankes, S. C. (2003). Shaping the next one hundred years: new methods for quantitative, long-term policy analysis (0833034855). Retrieved from Santa Monica, California, USA:

Letcher, R., Jakeman, A., \& Croke, B. (2004). Model development for integrated assessment of water allocation options. Water Resources Research, 40(5). doi:10.1029/2003WR002933

Maier, H. R., Guillaume, J. H. A., van Delden, H., Riddell, G. A., Haasnoot, M., \& Kwakkel, J. H. (2016). An uncertain future, deep uncertainty, scenarios, robustness and adaptation: How do they fit together? Environmental Modelling \& Software, 81, 154-164. doi:10.1016/j.envsoft.2016.03.014

Matrosov, E. S., Padula, S., \& Harou, J. J. (2013). Selecting portfolios of water supply and demand management strategies under uncertainty-contrasting economic optimisation and 'robust decision making'approaches. Water Resources Management, 27(4), 1123-1148. doi:10.1007/s11269-012-0118-x

McPhail, C., Maier, H., Kwakkel, J., Giuliani, M., Castelletti, A., \& Westra, S. (2018). Robustness metrics: How are they calculated, when should they be used and why do they give different results? Earth's Future, 6(2), 169-191. doi:10.1002/2017EF000649

Moallemi, E. A., Elsawah, S., \& Ryan, M. J. (2018). Model-based multi-objective decision making under deep uncertainty from a multi-method design lens. Simulation Modelling Practice and Theory, 84, 232-250. doi:10.1016/j.simpat.2018.02.009

Moriasi, D. N., Arnold, J. G., Van Liew, M. W., Bingner, R. L., Harmel, R. D., \& Veith, T. L. (2007). Model evaluation guidelines for systematic quantification of accuracy in watershed simulations. Transactions of the ASABE, 50(3), 885-900. doi:10.13031/2013.23153

Moriasi, D. N., Zeckoski, R. W., Arnold, J. G., Baffaut, C., Malone, R. W., Daggupati, P., . . Wilson, B. N. (2015). Hydrologic and water quality models: Key calibration and validation topics. Transactions of the ASABE, 58(6), 1609-1618. doi:10.13031/trans.58.11075

Murray-Darling Basin Authority. (2010). Guide to the proposed Basin Plan. Retrieved from Canberra: https://www.mdba.gov.au/publications/archived-information/basin-plan-archives/guide-proposed-basin-plan

Murray Irrigation Limited. (2010). Response to the Guide to the Proposed Murray-Darling Basin Plan. Retrieved from http://www.murrayirrigation.com.au/media/2503/Submission\%20to\%20the\%20MDBA\%20re\%20Guide\%20to\%20t he\%20Proposed\%20Murray-Darling\%20Basin\%20Plan.pdf

Norton, J. (2015). An introduction to sensitivity assessment of simulation models. Environmental Modelling \& Software, 69, 166-174. doi:10.1016/j.envsoft.2015.03.020

Oreskes, N., Shrader-Frechette, K., \& Belitz, K. (1994). Verification, Validation, and Confirmation of Numerical Models in the Earth Sciences. Science, 263(5147), 641-646. doi:10.1126/science.263.5147.641

Pappenberger, F., \& Beven, K. J. (2006). Ignorance is bliss: Or seven reasons not to use uncertainty analysis. Water Resources Research, 42(5), n/a-n/a. doi:10.1029/2005WR004820

Pollino, C., Lester, R., Podger, G., Black, D., \& Overton, I. (2011). Analysis of South Australia's environmental water and water quality requirements and their delivery under the Guide to the proposed Basin Plan. Retrieved from Adelaide:

Refsgaard, J. C., \& Knudsen, J. (1996). Operational Validation and Intercomparison of Different Types of Hydrological Models. Water Resources Research, 32(7), 2189-2202. doi:10.1029/96WR00896

Refsgaard, J. C., van der Sluijs, J. P., Højberg, A. L., \& Vanrolleghem, P. A. (2007). Uncertainty in the environmental modelling process-a framework and guidance. Environmental Modelling \& Software, 22(11), 1543-1556. doi:10.1016/j.envsoft.2007.02.004

Reichert, P., \& Borsuk, M. E. (2005). Does high forecast uncertainty preclude effective decision support? Environmental Modelling \& Software, 20(8), 991-1001. doi:10.1016/j.envsoft.2004.10.005

Roach, T., Kapelan, Z., \& Ledbetter, R. (2015). Comparison of info-gap and robust optimisation methods for integrated water resource management under severe uncertainty. Procedia Engineering, 119, 874-883. doi:10.1016/j.proeng.2015.08.955

Roach, T., Kapelan, Z., Ledbetter, R., \& Ledbetter, M. (2016). Comparison of robust optimization and info-gap methods for water resource management under deep uncertainty. Journal of Water Resources Planning and Management, 142(9), 04016028. doi:10.1061/(ASCE)WR.1943-5452.0000660

Roberts, J., \& Marston, F. (2011). Water Regime of Wetland and Floodplain Plants: a Source Book for the Murray-Darling Basin. Canberra: National Water Commission.

Rogers, K., \& Ralph, T. (2010). Floodplain Wetland Biota in the Murray-Darling Basin. Collingwood: CSIRO Publishing.

Saltelli, A., Chan, K., \& Scott, E. M. (2000). Sensitivity analysis (Vol. 1): Wiley New York.

Saltelli, A., Tarantola, S., \& Campolongo, F. (2000). Sensitivity analysis as an ingredient of modeling. Statistical Science, 15(4), 377-395.

Schoemaker, P. J. (1995). Scenario planning: a tool for strategic thinking. Sloan management review, 36(2), 25. 
Strobl, C., Boulesteix, A.-L., Zeileis, A., \& Hothorn, T. (2007). Bias in random forest variable importance measures: Illustrations, sources and a solution. BMC Bioinformatics, 8(1), 25. doi:10.1186/1471-2105-8-25

Ticehurst, J. L., \& Curtis, A. L. (2015). Can existing practices expected to lead to improved on-farm water use efficiency enable irrigators to effectively respond to reduced water entitlements in the Murray-Darling Basin? Journal of Hydrology, 528, 613-620. doi:10.1016/j.jhydrol.2015.06.055

Tsoukiàs, A. (2008). From decision theory to decision aiding methodology. European Journal of Operational Research, 187(1), 138-161.

Tufte, E. R. (2001). The visual display of quantitative information (Vol. 2): Graphics press Cheshire, CT.

Vaishnavi, V. K., \& Kuechler, W. (2007). Using Patterns to Illuminate Research Practice. In Design Science Research Methods and Patterns (pp. 57-73): Auerbach Publications.

van Asselt, M., \& Rotmans, J. (1996). Uncertainty in perspective. Global Environmental Change, 6(2), 121-157. doi:10.1016/0959-3780(96)00015-5

Walker, W., Haasnoot, M., \& Kwakkel, J. (2013). Adapt or Perish: A Review of Planning Approaches for Adaptation under Deep Uncertainty. Sustainability, 5(3), 955. doi:10.3390/su5030955

Weimer-Jehle, W. (2006). Cross-impact balances: A system-theoretical approach to cross-impact analysis. Technological Forecasting and Social Change, 73(4), 334-361. doi:10.1016/j.techfore.2005.06.005

Wickham, H. (2009). ggplot2: Elegant Graphics for Data Analysis: Springer-Verlag New York,.

Williams, B. K. (2011). Passive and active adaptive management: Approaches and an example. Journal of Environmental Management, 92(5), 1371-1378. doi:10.1016/j.jenvman.2010.10.039

Yee, J. S. R. (2010). Methodological Innovation in Practice-Based Design Doctorates. Journal of Research Practice, 6(2), 1515.

Zhang, M., Yue, P., Wu, Z., Ziebelin, D., Wu, H., \& Zhang, C. (2017). Model provenance tracking and inference for integrated environmental modelling. Environmental Modelling \& Software, 96, 95-105. doi:https://doi.org/10.1016/j.envsoft.2017.06.051 